IZA DP No. 9103

Financial Literacy and Food Security in Extremely Vulnerable Households

Daniel L. Millimet

Ian K. McDonough

Thomas B. Fomby

June 2015 


\title{
Financial Literacy and Food Security in Extremely Vulnerable Households
}

\author{
Daniel L. Millimet \\ Southern Methodist University \\ and IZA \\ Ian K. McDonough \\ University of Nevada, Las Vegas \\ Thomas B. Fomby \\ Southern Methodist University
}

Discussion Paper No. 9103
June 2015

IZA
P.O. Box 7240
53072 Bonn
Germany

Phone: +49-228-3894-0

Fax: +49-228-3894-180

E-mail: iza@iza.org

Any opinions expressed here are those of the author(s) and not those of IZA. Research published in this series may include views on policy, but the institute itself takes no institutional policy positions. The IZA research network is committed to the IZA Guiding Principles of Research Integrity.

The Institute for the Study of Labor (IZA) in Bonn is a local and virtual international research center and a place of communication between science, politics and business. IZA is an independent nonprofit organization supported by Deutsche Post Foundation. The center is associated with the University of Bonn and offers a stimulating research environment through its international network, workshops and conferences, data service, project support, research visits and doctoral program. IZA engages in (i) original and internationally competitive research in all fields of labor economics, (ii) development of policy concepts, and (iii) dissemination of research results and concepts to the interested public.

IZA Discussion Papers often represent preliminary work and are circulated to encourage discussion. Citation of such a paper should account for its provisional character. A revised version may be available directly from the author. 


\section{ABSTRACT \\ Financial Literacy and Food Security in Extremely Vulnerable Households}

Food insecurity is one of the most, if not the most, significant, nutrition-related public health issue confronted in the US. Unfortunately, we know very little about the determinants of food security except that it is not synonymous with poverty. Many households above the poverty line are food insecure; many below are not. We investigate a lack of financial literacy as a potential salient determinant of household-level food security. In light of the recent financial crisis and the burgeoning literature on financial literacy, we know that inadequate financial skills and practices are a significant problem that spans all socioeconomic groups. Using original survey data collected among food pantry clients in North Texas, we assess the causal effect of financial literacy on food security. Our results indicate a strikingly significant effect, both economically and statistically.

JEL Classification: I12, I18

Keywords: food security, financial literacy, poverty

Corresponding author:

Daniel L. Millimet

Department of Economics

Southern Methodist University

Box 0496

Dallas, TX 75275-0496

USA

E-mail: millimet@smu.edu

\footnotetext{
* This research was made possible by a grant through the Hunger Center of the North Texas Food Bank. The authors are especially grateful to Richard Amory at the North Texas Food Bank. The authors thank Lynn Stokes for help with the sampling design and participants at the Three Square research conference.
} 


\section{Introduction}

The US Department of Agriculture (USDA) uses the Food Security Module, an 18 question survey module, to classify households into four levels of food security: very low food secure, low food secure, marginally food secure, and high food secure 1 Together, the first two categories comprise the group of food insecure households, while the final two categories comprise the group of food secure households. The numbers are startling and reveal a lack of food security to be one of the most pressing issues facing the US today. Although the rise in US households classified as food insecure has tapered off since the Great Recession, 17.5 million households (14.3\%) were still classified as food insecure in 2013, indicating the absence of sufficient, reliable access to food due to a lack of money and/or other resources. Of these households, 6.8 million (5.6\%) are classified as very low food secure. Focusing on households with children present, 3.8 million households (or 9.9\%) were classified as having food insecure children in 2013. Another 360,000 households (0.9\%) are classified as having children with very low food security (Coleman-Jensen et al. 2014). These figures represent a significant increase above pre-recession (2007) levels, and food insecurity has been characterized as "one of the most important and high profile nutrition-related public health issues in the United States today" (Gundersen et al. 2011, p. 282).

The consequences of food insecurity are relatively well known, severe, and potentially long-lasting. Gundersen et al. (2011) provide a nice survey of the literature, which emphasizes the associations between food insecurity and a wide range of health problems ranging from birth defects to mental health issues to cognitive impairment. However, the determinants of food insecurity are less well understood (Gundersen and Gruber 2001; Gundersen et al. 2011). Existing studies have focused primarily on household-level economic resources measured by income, poverty status, and participation in federal nutrition assistance programs (most notably the Supplemental Nutrition Assistance Program (SNAP), National School Lunch Program (NSLP), and Special Supplemental Nutrition Program for Women, Infants, and Children (WIC)). Recent analyses have focused on long-term measures of income, and the role played by income volatility and liquid and non-liquid assets.

While these household-level factors do have significant explanatory power in explaining variation in food security, the residual variation remains substantial. In particular, household economic resources are far from the entire story; $57.9 \%$ of households with an income below the poverty level were food secure in 2013, while $6.7 \%$ of households with an income exceeding 185 percent of the poverty line were food insecure (ColemanJensen et al. 2014). The established, positive relationship between income and food security is as expected (Gundersen and Gruber 2001; Leete and Bania 2010; Dahl et al. 2014). However, the substantial fraction of poor households that are food secure and the large portion of non-poor households that are food insecure is counterintuitive and in need of explanation.

To help understand the variation in food security conditional on household economic resources, several studies have considered - explicitly or through conjecture - more aggregate determinants of household

\footnotetext{
${ }^{1}$ See http://www.ers.usda.gov/topics/food-nutrition-assistance/food-security-in-the-us/measurement.aspx
} 
experiences. Examples include residential type (urban, suburban, or rural), macroeconomic conditions such as the unemployment rate and tax rates, food and housing prices, food accessibility, residential mobility, and local infrastructure concerning federal nutrition programs (e.g., benefit generosity, stigma, and transaction costs) (Bartfeld and Dunifon 2006; Guo 2011). Despite this growing literature, no studies, to our knowledge, have investigated the causal effect of financial literacy and household financial practices on food security. Gundersen and Garasky (2012) do explore the association between self-assessed financial management skills and food security, but do not address issues related to measurement error or unobserved heterogeneity. As such, their results are not be intended to be interpreted in a causal manner. Nonetheless, this association, in combination with recent evidence on the importance of financial literacy on a host of economic outcomes (e.g., Lusardi and Mitchell 2014), suggests that financial literacy may be pivotal to understanding the prevalence food security conditional on household resources.

As stated in Gundersen and Garasky (2012), examining the causal effect of financial literacy on food security is difficult since there is little survey data incorporating information on both food security and financial literacy. We overcome this difficulty using original data collected from a self-designed survey administered to 1,009 individuals utilizing food pantries across North Texas in 2014. The survey includes the Food Security Module along with detailed information on financial literacy and household financial behaviors. We utilize this information to devise a composite index of household financial literacy. Finally, we apply instrumental variable (IV) estimation - relying on exclusion restrictions explicitly incorporated into the survey for this purpose - to estimate the causal effect of financial literacy on food security in extremely vulnerable households. Our survey thus provides a unique opportunity to address the research question at hand.

Our results are quite striking. Financial literacy is found to have a statistically and economically large impact on the probability of a household being food insecure. In particular, our preferred estimates imply that increasing our index of financial literacy by one standard deviation reduces the probability of a household being food insecure by 18 percentage points. Moreover, one standard deviation is not an unreasonable increase; moving from the $25^{\text {th }}$ to the $75^{\text {th }}$ percentile of the empirical distribution of financial literacy in our sample corresponds to an increase of 1.4 standard deviations. If one is willing to extrapolate this result from North Texas to the entire US, our finding implies that a nationwide one standard deviation increase in financial literacy across the 17.5 million US households characterized as food insecure in 2013 would have elevated roughly 3.2 million households to food secure. In other words, a one standard deviation increase in financial literacy would reduce the prevalence of food insecurity from $14.3 \%$ of households to $11.7 \%$.

Our findings are equally as stark when examining very low food security. A similar one standard deviation increase in financial literacy reduces the probability of a household being very low food secure by 20 percentage points. Extrapolating to the 6.8 million US households characterized as very low food secure in 2013, a nationwide one standard deviation increase in financial literacy would have elevated roughly 1.4 million U.S. households to at least low food security. In other words, a one standard deviation increase in 
financial literacy would reduce the prevalence of very low food security from $5.6 \%$ of households to $4.5 \%$. Exploring the heterogeneity in the marginal impact of boosting financial literacy along the dimensions of race and gender do not reveal substantive differences. However, it appears that households initially at the upper end of the financial literacy distribution would benefit the most, on the margin, from financial literacy related interventions.

The remainder of the paper is organized as follows. Section 2 reviews the existing literature as it relates to financial literacy and food security. Section 3 describes the data and empirical strategy used for the analysis. Section 4 discusses the results. Finally, Section 5 concludes.

\section{Literature Review}

\subsection{Financial Literacy}

Traditional microeconomic theory asserts that fully rational and informed agents will attempt to smooth marginal utility over their lifetimes by consuming less (saving more) during periods of high earnings as a means of hedging against income shortfalls during periods when earnings are low (e.g., Friedman 1957). Further, it has been shown that agents' optimal behavior over their life cycle is influenced by individual preferences, the existence of public safety nets, liquidity constraints, and general economic conditions in asset markets (Attanasio and Weber 2010). However, implicit in this framework are rigid assumptions concerning the ability of agents to construct and execute complicated savings and decumulation plans and the ability of agents to navigate sophisticated financial markets. As pointed out in Lusardi and Mitchell (2014), very few individuals actually possess the financial knowledge required to project future income streams and interest rates, yet alone discount them appropriately. These abilities fall under the general heading of financial literacy.

In addition to its role in this traditional microeconomic model of intertemporal consumption behavior, the relevance of financial literacy to the decision making process of individuals has expanded greatly over time as credit and financial markets have become more accessible. In part this is evidenced by the recent shift in how individuals anticipate and plan for retirement. Previously, individuals in the work force relegated much of their retirement planning to third parties by relying heavily on social security and employer-sponsored, defined benefit pension plans. Today, however, individuals facing retirement must make an array of decisions including how much to save, where to invest, and how to decumulate wealth through the use of defined contribution plans and Individual Retirement Accounts (IRAs) (Lusardi and Mitchell 2014).

Aside from retirement planning, the recent financial crisis has brought to light numerous ways in which lower income households have increasing access to credit. For example, Smith and Hevener (2010) document the rise in subprime mortgages in the 1990s and early 2000s. From 1994 to 2003, the share of loans by subprime lenders rose from $4.5 \%$ to $9.0 \%$ and the total value of all subprime loan originations rose from $\$ 35$ billion to $\$ 335$ billion. By 2005, the share of subprime loans reached $21 \%$. Payday loans are another example 
of growing interactions between low income households and financial institutions. Bourke et al. (2012) report that 12 million US adults used payday loans in 2010, with the average borrower taking out eight loans of an average $\$ 375$ per loan. Lenders typically charge interest equivalent to a $391 \%$ annual percentage rate (APR). Borrowers report using such loans primarily to pay recurring expenses; $53 \%$ report using funds to pay regular expenses such as utilities, car payments, or credit card payments, $10 \%$ report using funds to pay rent or make a mortgage payment, and $5 \%$ report using funds to buy food.

Coinciding with this shift towards a more sophisticated and inclusive financial landscape, the literature on financial literacy has developed rapidly. On the theoretical side, recent contributions have sought to better understand incentives for acquiring financial literacy, as well as the role that financial literacy plays in the financial planning process. On the empirical side, attention has focused on the measurement of financial literacy and the costs of poor financial decisions.

The theoretical literature on financial literacy, motivated by the seminal work in Ben-Porath (1967) and Becker (1975), views the attainment of financial knowledge as a form of investment in human capital and examines the relationship between financial knowledge and savings decisions. Delavande et al. (2008) develop a two-period model where individuals can accumulate human capital by investing in financial knowledge. Though this additional investment in human capital comes at a cost, the acquisition of such knowledge allows individuals the ability to earn higher returns by being able to identify and access more sophisticated financial assets. Thus, as in the canonical model of human capital (e.g., Card 1999), investment in financial knowledge depends on costs, future returns, and the discount rate.

Japelli and Padula (2013) extend the theoretical literature on investment in financial literacy by proposing a multi-period model in which investment in financial knowledge is endogenously undertaken. The authors demonstrate that financial literacy and wealth are strongly related over the life cycle, with increased investment and wealth until retirement and a decline in both thereafter. The authors further show that in economic systems where savings decisions are intermediated by some central authority, incentives to save, generate wealth, and hence invest in financial knowledge are diminished.

Lusardi et al. (2011, 2013) build on these initial models by incorporating additional complexities that are now commonplace in models of savings behavior such as borrowing constraints, shocks to both health and earnings, equity market returns, mortality risks, and other demographic factors. The authors address these deficiencies by calibrating and simulating a dynamic life cycle model where agents choose both capital market investments and investments in financial knowledge. The model yields several important predictions.

First, the optimal path of financial knowledge follows an inverted-U shape over the life cycle. Specifically, individuals invest in financial knowledge up to the point where the marginal benefit equals the marginal cost (in terms of time and money). This leads to the accumulation of financial knowledge early in life, followed by a lapse in financial knowledge later in life. Second, inequality in wealth and financial knowledge arise endogenously, with differences in wealth across groups with varying levels of education also arising endogenously. This occurs since some subpopulations rationally underinvest in financial knowledge in anticipation 
of having access to public safety nets. Third, the authors conclude that policy interventions relating to financial literacy programs for the least educated may do very little in mitigating wealth inequality if relying on safety nets is less costly than acquiring additional financial knowledge.

The preceding theoretical literature highlights three core skills instrumental in decision making regarding life cycle savings and investment: (i) the numerical ability to do calculations related to discounting, (ii) an understanding of prices and inflation, and (iii) an understanding of the risk associated with diversification (Lusardi and Mitchell 2014). To empirically measure these skills in individuals, and examine their relationship to various financial behaviors, Lusardi and Mitchell (2008, 2011a) create a set of three questions that have been implemented in surveys administered in both the US and abroad.

These three questions were first added to the 2004 Health and Retirement Study (HRS), which was administered to a representative sample of US individuals who were 50 years and older. Analyzing the results, Lusardi and Mitchell (2011a) find that, on average, this population of older adults is fairly financially illiterate. Roughly half of the respondents could not answer the discounting and inflation questions, and one-third could not answer the question related to financial diversification. The authors note that these results are somewhat surprising since this demographic group has lived through multiple periods of high inflation and witnessed multiple shocks to both asset markets and broader economy.

As noted in Lusardi and Mitchell (2014), these same three questions have been added to other surveys including the 2007-2008 National Longitudinal Survey of Youth (NLSY) for individuals in the age range of 23-38 (Lusardi et al. 2010), the RAND American Life Panel (ALP) spanning all ages (Lusardi and Mitchell 2009), and the 2009 and 2012 National Financial Capability Study (Lusardi and Mitchell 2011b). In each of these studies, the authors confirm - and even extend to younger age groups - that the level of financial literacy in the US is astonishingly low. Similarly, Mandell (2008) find that individuals in high school, like their adult counterparts, demonstrate an inadequate level of financial knowledge.

In an international context, again using variants of the same three questions about interest rates, inflation, and risk diversification, multiple studies have set out to measure the level of financial literacy across the age distribution in multiple countries. Like in the US, few people are able to answer correctly the three basic financial literacy questions. In light of these findings, it appears that the scarcity of financial knowledge among individuals in the US and abroad appear to be independent of country and/or stage of development ${ }^{2}$ In an attempt to get at the underlying cause(s) of financial literacy, Grohmann et al. (2014), using data from collected from households in Thailand, conclude that important mitigating factors for poor financial literacy are family background attributes. In particular, the educational attainment of mothers and parental encouragement to save appear to matter most.

More recently, Lusardi et al. (2014) extend the literature by measuring financial sophistication among older adults in addition to financial literacy. The authors find that older respondents lack financial sophistication as well as financial literacy. This older group of individuals fails to grasp the basics of risk

\footnotetext{
${ }^{2}$ See Table 2 in Lusardi and Mitchell (2014) for a list of papers.
} 
diversification, asset valuation, portfolio choice, and an understanding of investment fees.

In light of the recent financial crisis and this newfound evidence of a lack of financial literacy and sophistication, empirical researchers have turned their attention to the direct costs associated with a lack of financial literacy. On the investment side, many lacking requisite financial knowledge forego greater asset market returns due to excessive fees, trading costs, and a lack of portfolio diversification (Calvet et al. 2007; French 2008). A lack of financial literacy, in particular debt literacy, has also been shown to be related to US homeowners suboptimally refinancing their homes, engaging in poor credit card behavior, and leveraging high cost forms of borrowing such as cash advances and payday loans (Ernst et al. 2004; Campbell 2006; Lusardi and Tufano 2009). Finally, it stands to reason that higher levels of financial literacy among retirees should be associated with more informed, 'once in a lifetime' financial decisions, such as when to claim Social Security and/or other pension benefits. In particular, it is reasonable to think that elevated levels of financial literacy would help mitigate costly missteps associated with navigating such complex, later-in-life financial matters (Lusardi and Mitchell 2014).

In sum, the literature on financial literacy, while still in its relative infancy, suggests that financial literacy should be viewed no differently than other forms of human capital. However, investment in this type of human capital is woefully lacking, leading individuals from all age and socioeconomic groups to make poor financial decisions resulting in lower household welfare.

\subsection{Food Security}

The existing literature on food security is equally compelling. As noted in the Introduction, millions of households in the US are food insecure. The most recent USDA report (Coleman-Jensen et al. 2014) indicates that although the number of U.S. households classified as food insecure has declined slightly over the past few years - from $14.9 \%$ of all households in 2011 to $14.3 \%$ in 2013 - it remains substantially higher than prior to Great Recession. In 2000, 10.5\%. of households were food insecure. In terms of individuals affected, 49.1 million individuals resided in food insecure households in 2013 (up from 33.2 million in 2000); 17.1 million individuals resided in households with very low food security in 2013 (up from 8.5 million in 2000). There is also substantial state-level variation in food security. North Dakota has the lowest rates of food insecurity $-8.7 \%$ of households are food insecure and $3.1 \%$ are very low food secure - while Arkansas has the highest rates $-21.2 \%$ and $8.4 \%$, respectively.

The consequences of a lack of food security are known to be severe and non-transitory, and as such the number of households classified as food insecure represents a serious public health concern (Gundersen 2013). Among children, an insufficient, unreliable source of food is associated with a litany of health-related problems (Gundersen et al. 2011; Gundersen 2013). Health-related problems include an increased probability of being anemic and lacking other essential nutrients (Cook et al. 2004; Eicher-Miller et al. 2009), increased chance of having asthma (Kirpatrick et al. 2010), increased incidence of behavioral problems including increased levels of aggression and anxiety (Whitaker et al. 2006), an overall decreased level of physical health (Cook 
et al. 2006), overall poorer scores on health exams (Stuff et al. 2004), and decreased cognitive development during the early years of schooling (Howard 2011).

The consequences are equally far reaching for adults, including lower levels of nutrient uptake (McIntyre et al. 2003; Kirkpatrick and Tarasuk 2007) and increased physical and mental health problems including diabetes and depression (Whitaker et al. 2006; Seligman et al. 2010). Elderly adults lacking food security face these same issues, as well having a higher probability of facing impediments on basic, daily activities (Ziliak et al. 2008).

In light of these well known consequences, a growing body of literature has emerged attempting to understand the underlying determinants of food security. The most well established factors associated with food security are, perhaps not surprisingly, socioeconomic and demographic measures. As reported in Gundersen et al. (2011) and Coleman-Jensen et al (2014), higher levels of food insecurity are associated with households having incomes at or below the federal poverty line and households headed by single parents, African-American and Hispanic individuals, renters, and less educated individuals. As well, food insecurity is also more prevalent in large cities and rural areas relative to suburban areas and areas on the periphery of large cities. Coleman-Jensen (2011) further finds that households in which the primary earner's employment is defined by holding multiple jobs, working varied hours, or working a part-time job are more likely to be food insecure relative to a household where the head has secured regular, full-time employment.

However, the puzzle that arises from the empirical studies to date is the variation in food security that is not explained by current household economic resources. Using the 2009 Supplement for the Current Population Survey, Gundersen (2013) shows that high proportions of households below the poverty line are food secure while a large number of households above the poverty line are food insecure given. In addition to the figures given in the Introduction, the data in Coleman-Jensen et al. (2014) indicate that 38.9\% and $16.0 \%$ of households with an income less than 130 percent of the federal poverty line were food insecure and very low food secure, respectively, in 2013. Thus, $60.1 \%$ of households with an income less than 130 percent of the federal poverty line were food secure. In contrast, $90.7 \%$ of households with an income exceeding 130 percent of the federal poverty line were food secure. However, $9.3 \%$ and $3.3 \%$ of households with an income exceeding 130 percent of the federal poverty line were food insecure and very low food secure, respectively.

These puzzling figures suggest, when combined with the findings from the literature on financial literacy, that a lack of financial knowledge, which spans households above and below the poverty line, could be an important component to understand food security. Indirect evidence that this may be the case can be found in existing studies. Gundersen and Gruber (2001) find that household income averaged over a two-year window is a better predictor of food security than current income. Moreover, liquid assets are also found to be a crucial determinant of food security. Similarly, Ribar and Hamrick (2003) find that assets and income volatility are important determinants of food security. Leete and Bania (2010) find that liquidity constraints are a critical predictor of food security. Finally, Gundersen and Garasky (2012) explore the association between self-assessed financial management skills and food security and document an economically and 
statistically significant relationship between an individual's use of specific financial management practices and food security, as well as between a respondent's level of confidence in their financial management skills and food security. However, the ability to interpret this finding as causal is not clear as the authors do not address the potential measurement error and endogeneity issues associated with measures of financial management skills 3

\section{Empirics}

\subsection{Data}

To explore the causal impact of financial literacy on food security levels for vulnerable households, we collected original data focusing on extremely vulnerable households. To that end, we surveyed individuals at randomly selected pantries served by the North Texas Food Bank (NTFB) across North Texas during March - September 2014. The sample was selected with the goal of achieving a random sample of roughly 1,000 individuals from the population frequenting NTFB pantries. Appendix A provides details regarding the survey administration.

Our final sample includes 1,009 individuals from 38 pantries. The data contain a wealth of information at the individual and household level, including information on basic demographics, educational backgrounds, household composition, levels of income and debt, self reported health status and behaviors, criminal background, and household food situation. Of particular relevance, we included the USDA Food Security Module in the survey to measure food security along with detailed questions regarding financial literacy and behaviors. We discuss the specific measures of financial literacy and behaviors below. Table 1 presents basic summary statistics for the variables utilized in the analysis here. Note, not all 1,009 respondents answered every question. Thus, we report the sample size along with each measure.

The age range of the sample varies from 16 to 86 years old, with the average age around 48 years old. The majority of the sample is female (nearly $80 \%$ ). The racial breakdown is fairly uniform; $29 \%$ identify as white, non-Hispanic, $38 \%$ identify as black, non-Hispanic, and $27 \%$ identify as Hispanic. Nearly $80 \%$ of the sample is US born; the vast majority of those born abroad were born in Mexico. This is also reflected in the primary language spoken in the households of the respondents; English is the primary language in nearly $80 \%$ of the sample with Spanish accounting for nearly all the remainder.

In terms of educational background, $30 \%$ of the sample reports either not attending high school at all (10\%) or attending but not graduating (20\%). Thirty-five percent of the sample possess a high school diploma or GED and $19 \%$ attended college, but did not complete a degree. Five percent of the sample has obtained a postsecondary award or certificate (such as hairstylist license) and another $5 \%$ has earned an associate's degree. Finally, $6 \%$ of the sample reports having completed at least a four-year degree.

\footnotetext{
${ }^{3}$ See Lusardi and Mitchell (2014) for a complete discussion related to the measurement error and endogeneity problems associated with measures of financial literacy.
} 
Related to household composition, $32 \%$ of the sample is married, while $26 \%$ of the sample has never been married. The remainder are either divorced, separated, or widowed. Finally, $43 \%$ of the sample currently resides with either a spouse or partner. The average household size is 3.2 , with 1.3 members being below the age of 18 on average.

When gathering data on household income, we include all sources of income obtained over the prior month. We find that $18 \%$ of the sample reports a combined household income of less than $\$ 600 ; 7 \%$ less than $\$ 200$. The modal response, representing $18 \%$ of the sample, is an income between $\$ 600$ and $\$ 799$. Another $28 \%$ of the sample reports a household income between $\$ 800$ and $\$ 1,249$, while $25 \%$ report a household income between $\$ 1,250$ and $\$ 1,999$. The remaining $8 \%$ of the sample claim a household income in excess of $\$ 2,000$ in the prior month.

When measuring household debt, the reported figure represents the combined debt of all household members at the time of the survey. The modal response, representing $28 \%$ of the sample, is a debt level below $\$ 200$. However, $23 \%$ of the sample report a debt level between $\$ 2,000$ and $\$ 9,999$ and another $23 \%$ of the sample report a debt level in excess of $\$ 10,000$. Of the remainder, $9 \%$ report a debt level between $\$ 200$ and $\$ 999$ and $8 \%$ report a debt level between $\$ 1,000$ and $\$ 1,999$.

To get at direct measures of food insecurity, we incorporate the USDA's Food Security Module into the survey. The module contains 18 questions, the first ten of which pertain to all households (specifically, any household with an adult) while the final eight questions only pertain to households with children under the age of 18. All questions are one of three types: (i) yes/no, (ii) often/sometimes/never, or (iii) almost every month/some months but not every month/only 1 or 2 months. "Yes," "often," "sometimes," "almost every month", and "some months but not every month" are counted as affirmative responses.

Households with no children giving zero affirmative responses are classified as having high food security. Households with no children giving 1-2 affirmative responses are classified as having marginal food security. Households with no children giving 3-5 affirmative responses are classified as having low food security. Households with no children giving 6-10 affirmative responses are classified as having very low food security. For households with children, zero affirmative responses indicates high food security, 1-2 affirmative responses indicates marginal food security, 3-7 affirmative responses indicates low food security, and 8-18 affirmative responses indicates very low food security.

Having obtained individual responses, we then map the responses, given the household composition, to one of four levels of food security set forth by the USDA. Upon doing so, we find that $5 \%$ of the respondents' households are classified as having high food security, $12 \%$ are classified as having marginal food security, $83 \%$ are classified as having low or very low food security, with $46 \%$ classified as having very low food security. Thus, not surprisingly, the respondents predominantly find themselves in a very tenuous situation with regards to their food security. Nonetheless, there is variation in the degree of food security within the sample of pantry-going individuals.

To collect data on financial literacy and behaviors, we relied heavily on existing question designs. See 
Appendix A for a copy of the survey questions. Specifically, we first ask ten questions to measure understanding of interest rates, inflation, taxes and withholdings, and personal credit. Two of these questions are borrowed from the 2004 HRS mentioned above, one comes from additional financial literacy questions incorporated in the 2009 National Financial Capability Study (NFCS), and one comes from the 2009 RAND American Life Panel (survey 64) $]^{4}$ The remaining six questions are borrowed from the National Endowment for Financial Education (NEFE) Financial Evaluation Toolkit 5 Out of the 1,009 respondents, only twelve $(0.99 \%)$ were able to answer all ten questions correctly. Further, only $48 \%$ were able to answer more than five of the ten questions correctly. The modal score, representing $16 \%$ of the sample, is six correct responses.

The next two questions related to self-assessed financial confidence and the financial confidence of one's parents during childhood. Own and parental confidence were reported on a Likert-type scale from one to five, with five representing very confident. The median (and modal) response when individuals were asked about their own level of confidence is three out of five, which represents $32 \%$ of the sample. When asked to rate their parent's level of confidence, the median response, representing $25 \%$ of the sample, is four out of five, with the modal response, representing $35 \%$ of the sample, being five out of five.

The next set of eight questions asked individuals about their current financial behaviors, such as using a checking account to pay bills, reviewing bills for accuracy, paying bills on time, setting personal financial goals, using a budget and tracking spending, looking for ways to decreases spending, and reviewing income before making large purchases. Each question permitted answers on a scale from zero to five, with five corresponding to engaging in the behavior all the time. Aggregating scores across the eight questions yields a total possible score of 40 . The median aggregate score is 27 out of 40 ( $4 \%$ of the sample), with the modal score being 30 out of 40 ( $7 \%$ of the sample).

Finally, we asked respondents four questions designed to measure beliefs related to the importance of savings and budgeting, keeping track of spending, and establishing an emergency savings fund. Responses correspond to a standard, five-point Likert scale. Aggregating scores across the four questions yields a total possible score of 20 . The median aggregate score is 17 out of 20 (11\% of the sample), with the modal score being 16 out of 20 ( $21 \%$ of the sample).

To construct a single measure of financial literacy and behaviors, we begin with four variables: (i) number of correct responses (out of ten) from the first set of financial knowledge questions, (ii) self-assessed own financial confidence (out of five), (iii) aggregate score regarding current financial behaviors (out of 40), and (iv) aggregate score regarding current financial beliefs (out of 20). Using these four variables, we utilize Principal Components Analysis (PCA) to create a single index of financial literacy and practices. This index of financial literacy, standardized to be mean zero and have unit variance, is the covariate of interest in our empirical analysis.

Before turning to our analysis, it is worth comparing our sample to the national sample and Texas sample used in the Hunger in America 2014 (HIA 2014) survey. HIA 2014 is the most recent survey conducted by

\footnotetext{
${ }^{4}$ See https://alpdata.rand.org/index $\cdot$ php?page=data\&p=showsurvey\&syid=64

${ }^{5}$ See http://toolkit.nefe.org/Portals/0/Toolkit-Manual.pdf
} 
Feeding America; the survey project has taken place every four years since 1993. HIA 2014 surveys individuals who utilized food programs supported by Feeding America in 2012-2013. Feeding America operates in all 50 states, Washington DC, and Puerto Rico. It distributes more then three billion pounds of food and grocery products per year and provides more then $\$ 30$ million in local anti-hunger grants. By comparing our sample to that in HIA 2014, we can assess the representativeness of North Texas food pantry clients to the national population of such clients.

At the national level, the majority of individuals served directly by Feeding America (annually) fall in the age range of 30-39 years old (26.0\%) with $43.4 \%$ of all individuals identifying as white, non-Hispanic, $26.1 \%$ identifying with black, non-Hispanic, and $19.7 \%$ identifying with Hispanic. The vast majority of survey respondents are female (66.7\%). In terms of educational background, $26.1 \%$ of individuals have less than a high school diploma, $46.4 \%$ have a high school diploma or GED, and $7.1 \%$ report have a license, certificate, or some degree beyond high school. Another $14.8 \%$ have some college or a two-year degree and $5.7 \%$ report having earned a four-year degree or higher. Looking at income, the modal response for monthly household income is $\$ 501-\$ 1000$ (29.6\%), with a median monthly income level of $\$ 927$. When evaluating client households by level of food security, $16.2 \%$ are classified as food secure and $83.8 \%$ are food insecure. In households with at least one child, $11.2 \%$ are classified as food secure and $88.8 \%$ are classified as food insecure.

Turning to North Texas, the majority of individuals in HIA 2014 fall within the age range of 30-39 years old $(33.4 \%)$ with $31.1 \%$ of all individuals identifying as white, non-Hispanic, $31.1 \%$ identifying as black, non-Hispanic, and $29.4 \%$ identifying with Hispanic. Twenty-six percent of the individuals have less than a high school diploma, $46.6 \%$ have earned a high school diploma or GED, and 6.9\% have earned a license, certificate, or some degree beyond high school. Another 15.5\% have some college or two-year degree and $5 \%$ have earned a four-year degree or higher. In terms of income, the modal response based on reported annual income is in the range of $\$ 1-\$ 10,000(35 \%)$. Looking at annual incomes relative to the poverty line, $73 \%$ of households are at or below the poverty level. With respect to food security, $83 \%$ of client households are classified as food insecure. Thus, our sample composition seems quite comparable to the HIA North Texas and national samples of food pantry clients.

\subsection{Estimation}

To identify the causal impact of financial literacy and practices on household food security, we estimate both a Linear Probability Model (LPM) and a Probit model. Specifically, we begin by estimating

$$
y_{i}=\alpha+\gamma F_{i}+X_{i} \beta+\varepsilon_{i}, \quad i=1, \ldots, N
$$

where $y$ is equal to one if individual $i$ is classified as either food insecure or very low food secure and zero otherwise, $F$ is our scalar index of financial literacy, $X$ is a $1 \times(K-1)$ vector of covariates, $\gamma$ is the coefficient 
of primary interest, and $\varepsilon$ is a mean zero error term. The vector $X$ includes all the covariates listed in Table 1. In addition, we include zip code fixed effects in the model.

Ordinary Least Squares (OLS) estimation of (1) is not likely to yield an unbiased or consistent estimate of $\gamma$ for two reasons. First, as financial literacy is a nebulous concept, any empirical measure is apt to be imprecise. As stated in Lusardi and Mitchell (2014, p. 10-11), "Naturally, any given set of financial literacy measures can only proxy for what individuals need to know to optimize behavior in intertemporal models of financial decision making. Moreover, measurement error is a concern, as well as the possibility that answers might not measure 'true' financial knowledge." Second, unobserved individual attributes, such as innate ability, that are likely to influence financial literacy are also likely to be correlated with food security (Lusardi and Mitchell 2014).

To overcome both of these econometric challenges, we estimate (1) via Generalized Method of Moments (GMM) using the respondent's perception of their parents' confidence related to financial matters and the number of cigarettes smoked daily by all household members as IVs. The spirit of both instruments follows from the financial literacy literature. As stated previously, because financial literacy can be viewed as a form of human capital, requiring investment to acquire, factors affecting the costs and benefits of this investment, but not impacting food security, represent valid exclusion restrictions. Parental confidence may impact the acquisition of financial human capital during childhood as it lowers the investment cost; parents are potentially a readily available source of information (Grohmann et al. 2014). Smoking, on the other hand, has been posited to be related to individual discount rates (Fersterer and Winter-Ebmer 2003). Because a higher discount rate reduces the benefit of investing in human capital (since the costs are borne immediately, but the returns are relegated to the future), a proxy for an individual's discount rate, such as smoking, should represent a valid instrument. In other specifications, we also make use of questions included in the survey explicitly designed to measure individual discount rates. However, because the questions are purely hypothetical, our preferred specification uses smoking as the instrument.

As noted in Horrace and Oaxaca (2006), a serious concern associated with estimating a LPM (despite its popularity) is that very stringent conditions need to be satisfied to obtain consistent estimates. To handle these concerns, while still addressing the econometric challenges detailed above, we estimate an IV Probit model via maximum likelihood ${ }^{6}$ In particular, we estimate

$$
\begin{aligned}
y_{i} & =\mathbb{I}\left(\alpha+\gamma F_{i}+X_{i} \beta+\varepsilon_{i}>0\right), \quad i=1, \ldots, N \\
F_{i} & =\pi_{0}+X_{i} \pi_{1}+Z_{i} \pi_{2}+\nu_{i}
\end{aligned}
$$

where $\mathbb{I}(\cdot)$ is the indicator function, $Z$ are the instruments outlined above, $(\varepsilon, \nu) \sim \mathbb{N}(0, \Sigma)$, and everything else is as defined previously.

\footnotetext{
${ }^{6}$ Estimation is performed using the -ivprobit- command in Stata.
} 


\section{Results}

Results from our preferred specifications are presented in Tables 2 and 3. Table 2 defines the outcome, $y$, as one if the household is food insecure (i.e., either low or very low food secure) and zero otherwise. Table 3 defines the outcome, $y$, as one if the household is very low food secure and zero otherwise. Within each table, we report OLS, GMM, and IV Probit estimates, where the latter are converted to average marginal effects for comparability, of four specifications. The specifications differ in the variables included in $X$. Finally, for the GMM estimates, we include a battery of specification tests regarding the quality of the instruments.

\subsection{Food Insecurity}

Turning to the results for food insecurity (Table 2), we obtain three key findings. First, the effect of financial literacy obtained via OLS is negative, but small, and only statistically significant in specification (1) where no other controls are included. Because the index of financial literacy is normalized to have unit variance, the interpretation in this specification is that a one standard deviation improvement in financial literacy is associated with a 3.0 percentage point decline in the probability of being low food secure. Controlling for individual and household observables, as well as zip code fixed effects, reduces the association to only 1.8 percentage points.

Second, our identification strategy appears sound. In all four specifications, the underidentification test rejects the null hypothesis that the model is not identified $(p<0.01)$, the overidentification test fails to reject the null hypothesis that the instruments are valid ( $p>0.32$ in all cases), and the Kleinbergen-Paap $F$-statistic is large indicating that weak instruments are not a concern $(F>16$ in all cases).

Third, addressing measurement error and/or unobserved heterogeneity matters. Consistent with prior empirical papers that instrument for financial literacy when examining other economic outcomes, addressing endogeneity leads to much larger effects of financial literacy in absolute value. Lusardi and Mitchell (2014, p. 27) state, "Interestingly, in all these cases, the IV financial literacy estimates always prove to be larger than the ordinary least squares estimates... It might be that people affected by the instruments have large responses, or there is severe measurement error, but on the other hand, it seems clear that the noninstrumented estimates of financial literacy may underestimate the true effect." Moreover, we easily reject the null of financial literacy being exogenous $(p<0.02$ in all cases).

In terms of the point estimates, we find that the GMM and IV Probit estimates are very similar and stable across the specifications. Generally, we obtain an estimated marginal effect of financial literacy on whether a household is food insecure of -0.180 . This is highly statistically significant according to both the usual, heteroskedasticity-robust standard errors and the Anderson-Rubin weak instrument robust test for statistical significance. As far as interpretation is concerned, the estimates imply that a one standard deviation increase in financial literacy results in an 18.0 percentage point decrease in the probability of a household being classified as food insecure. 


\subsection{Very Low Food Security}

When the outcome measures whether a household is very low food secure (Table 3), we get very similar results. As in Table 2, the OLS estimates are small and statistically insignificant. However, the GMM and IV Probit estimates are large (in absolute value), statistically significant, and stable (particularly across specifications (2) through (4)). Moreover, the instruments continue to perform well in terms of all the specification tests. In terms of the point estimates, we obtain an estimated marginal effect of financial literacy on whether a household is very low food secure of roughly -0.20 (IV Probit) to -0.25 (GMM). Thus, we estimate at least a 20 percentage point decrease in the probability of being classified as very low food secure given a one standard increase in financial literacy. Finally, the estimates are statistically significant according to both the usual, heteroskedasticity-robust standard errors and the Anderson-Rubin weak instrument robust test for statistical significance.

\subsection{Discussion}

As our results demonstrate, financial literacy is a crucial determinant of the food security of a household after controlling for observed attributes of households, location fixed effects, unobservable heterogeneity, and measurement error inherent in any index of individual financial literacy. Just how important it is, within this sample of extremely vulnerable households, is actually quite startling.

In terms of food insecurity, our estimates from specification (4) in Table 2 point to a marginal effect of 18 percentage points. This implies that an intervention that improves the financial literacy of all households in the US by one standard deviation - where a standard deviation is defined with respect to the empirical distribution of financial literacy in our sample - would be expected to reduce the number of food insecure households in the US from 17.5 million to 14.4 million (based on 2013 figures) 7 As noted previously, a one standard deviation is not an unreasonable increase. Moving from the $25^{\text {th }}$ to the $75^{\text {th }}$ percentile of the empirical distribution of financial literacy in our sample corresponds to an increase of 1.4 standard deviations.

Performing the same exercise for very low food security and using an estimated marginal effect of 20 percentage points, we again find that the broader impact is quite remarkable. In this case, an intervention that improves the financial literacy of all households in the US by one standard deviation - again defined with respect to the empirical distribution observed in our sample - would be expected to reduce the number of very low food secure households in the US from 6.8 million to 5.5 million (based on 2013 figures).

These calculations are based on average marginal effects. Of course, in the IV Probit model, marginal effects are observation-specific. This allows us to assess heterogeneities in the marginal effects across different groups. If such heterogeneities exist, then perhaps policies designed to improve financial literacy can be targeted where they will have the largest impact. To proceed, we examine variation in the marginal effects across groups defined on the basis of their current level of financial literacy, gender, and race.

\footnotetext{
${ }^{7}$ This, of course, assumes our estimates have external validity (i.e., are generalizable from North Texas to the US as a whole).
} 
To examine the marginal effects across the distribution of financial literacy, we discretize the cumulative distribution function (CDF) of financial literacy into deciles and then calculate the average marginal effects within each decile. For food insecurity, we find that the average marginal effect rises monotonically through the distribution. For example, for individuals in the bottom decile of financial literacy, a one standard deviation increase reduces the probability of being low food secure by 5.5 percentage points. The effect is 25.1 percentage points for individuals initially in the top decile. For very low food security, the average marginal effects are essentially uniform across the deciles. Specifically, the average marginal effect ranges from a low of 17.0 percentage points in the first decile to a high of 22.1 percentage points in the seventh decile.

When computing average marginal effects by gender, we find very little difference. The average marginal effects for males and females are -0.171 and -0.173 , respectively, for food insecurity and -0.203 and -0.204 , respectively, for very low food security. We similarly find little difference along racial lines. The average marginal effects for whites, blacks, and Hispanics are $-0.180,-0.187$, and -0.147 , respectively, for food insecurity; $-0.202,-0.213$, and -0.190 , respectively, for very low food security.

\subsection{Robustness}

To assess the robustness of our results, we undertake a few extensions. First, we augment the control set to include indicators for participation in the Supplemental Nutrition Assistance Program (SNAP), Temporary Aid for Needy Families (TANF), Special Supplemental Nutrition Program for Women, Infants, and Children (WIC), Supplemental Security Income (SSI) program, Medicare, Medicaid, and alternative public health insurance programs. We do not include these controls in our baseline specifications since they are arguably endogenous. Nonetheless, their inclusion has very little substantive effect on the estimated effect of financial literacy $]^{8}$

Second, we vary the instrument set. To start, we omit the instrument based on smoking. While smoking is related to an individual's discount rate and, hence, investment in human capital, it also potentially has a direct effect on food security conditional on household economic resources since expenditures on cigarettes may divert funds from food. Thus, Tables A1 and A2 are identical to Tables 2 and 3 except only parental financial confidence is used as an instrument. The results are essentially unchanged 9

We also augment the original instrument to include a third instrument: a direct measure of the survey respondent's discount rate. The survey contains a series of hypothetical questions about how much money one would be willing to accept one month from the time of the survey to forego the $\$ 20$ gift card the respondent was given at the time of the survey. As we had no way to track down the respondents one month later, these questions are purely hypothetical. As such, our preferred specifications utilize smoking as an instrument rather than this variable. Tables A3 and A4 are identical to Tables 2 and 3 except now the implied discount

\footnotetext{
${ }^{8}$ Results are available upon request.

${ }^{9}$ When using only parental financial confidence as an instrument, we also include smoking as a covariate in the model. The estimated coefficient is very small and never statistically significant ( $p>0.50$ in all cases). Results available upon request.
} 
rate is added to the instrument set. The results are qualitatively similar except the point estimates are a bit smaller, particularly in Table A3. In Table A4, when examining very low food security, the marginal effects are less impacted.

Finally, to understand which aspects of our financial literacy index are driving our results, we re-do the analysis replacing our composite index of financial literacy with standardized measures of each of the four components (knowledge, beliefs, behavior, and confidence). We estimate the models separately for each component; each model replaces the composite index with one of the components. The results, provided in Tables A5 and A6, yield several insights. First, the instruments are weak when instrumenting for financial knowledge and financial beliefs. Thus, while the point estimates continue to be negative and sometimes marginally statistically significant, the results are not reliable. Second, the instruments work well for the measures of financial behaviors and financial confidence. In both cases, the estimates are negative and statistically significant, but the marginal effects are twice as large for financial behaviors. A one standard deviation improvement in financial behaviors leads to roughly a 25 (30) percentage point decline in the probability of being food insecure (very low food secure). As such, our evidence is strongest for this measure of financial literacy (which corresponds to Question 13 in the survey in the appendix).

\section{Conclusion}

While food insecurity is a significant public health issue, addressing it is hampered by the fact that there exists substantial variation in food insecurity across households conditional on economic resources. The factors accounting for this residual variation remains a puzzle. Using original data collected from a selfdesigned survey administered to 1,009 individuals utilizing food pantries across North Texas in 2014, we assess the role played by financial literacy in this puzzle. Addressing issues related to measurement error and unobserved heterogeneity, our results point to a statistically and economically large causal effect of financial literacy on the probability of a household being food insecure. A one standard deviation increase in our index of financial knowledge, practices, and beliefs leads to a ceteris paribus 18 percentage point decline in the probability of being food insecure and at least a 20 percentage point decline in the probability of being very low food secure.

To put a one standard deviation increase in our index into a more interpretable form, we re-iterate that moving an individual from the $25^{t h}$ percentile of the sample distribution of our financial literacy index to the $75^{\text {th }}$ percentile constitutes an improvement of approximately 1.4 standard deviations. So, a one standard deviation improvement is less than what it takes to move from the bottom quartile to the top quartile. We also calculate the improvement in each of the four components of the index required to improve an individual's overall index by one standard deviation. Setting the other three components at the sample average, an individual's financial knowledge component would have to be raised by nine points on a 0-10 scale (or 3.5 standard deviations) in order for the overall index to improve by one standard deviation. An individual's 
financial beliefs component would have to be raised by 7 points on a 0-20 point scale (or 2.7 standard deviations) in order for the overall index to improve by one standard deviation. An individual's financial confidence component would have to be raised by 4 points on a 1-5 scale (or 2.9 standard deviations) in order for the overall index to improve by one standard deviation. Lastly, an individual's financial behaviors component would have to be raised by 18 points on a $0-40$ point scale (or 2.3 standard deviations) in order for the overall index to improve by one standard deviation. Thus, in terms of standard deviations, improving financial behaviors requires the smallest increase and, as noted when we analyzed the effects of each component on food insecurity separately, the strongest evidence for a causal effect on food insecurity is also for this component.

The magnitude and robustness of our findings suggest that financial literacy (and, in particular, financial practices) is a crucial factor in the determination of food security among vulnerable households. Additional research, which is difficult due to the lack of available data sources containing information on both financial literacy and food security, is clearly warranted in order to corroborate our conclusions.

Also warranted is research into effective ways to increase financial literacy, especially within vulnerable populations. Fortunately, such research is on-going. For example, Bertrand et al. (2004) discuss numerous options for increasing the savings and banking behavior among the 'unbanked' population such as establishing direct deposit for welfare benefits and Earned Income Tax Credit (EITC) refunds and having bank employees solicit the formation of new accounts at venues such as food pantries. More recently, research has focused on the ability of reminders and social pressure to influence individual financial behavior. Bracha and Meier (2015) document the ability of monthly text messages to alter the financial behavior of low income individuals in Boston, resulting in improved credit scores. Karlan et al. (2010) provide similar evidence of text and written messages improving saving rates in Bolivia, Peru, and the Phillipines. Kast et al. (2012) reach a similar conclusion using data from Chile. In terms of social pressure, Kast et al. (2012) find that selfhelp peer groups substantially increased savings rates among individuals in Chile. Similarly, Breza and Chandrasekhar (2015) document a substantial increase in savings in India when individuals are assigned to a 'monitor' within the village. Such research suggests the potential for incorporating financial reminders and social peer groups into the food pantry system in order to combat food insecurity. 


\section{References}

[1] Attanasio, O. and G. Weber (2010), "Consumption and Saving: Models of Intertemporal Allocation and Their Implications for Public Policy," Journal of Economic Literature, 43(3), 693-751.

[2] Bartfeld, J. and R. Dunifon (2006), "State-Level Predictors of Food Insecurity among Households with Children," Journal of Policy Analysis and Management, 25, 921-942.

[3] Becker, G. (1975), Human Capital: A Theoretical and Empirical Analysis, Second edition, New York: Columbia University Press.

[4] Ben-Porath, Y. (1967), "The Production of Human Capital and the Life Cycle of Earnings," Journal of Political Economy, 75, 352-265.

[5] Bertrand, M., S. Mullainathan, and E. Shafir (2004), "A Behavioral-Economics View of Poverty," American Economic Review, 94(2), 419-423.

[6] Bourke, N., A. Horowitz, and T. Roche (2012), "Payday Lending in America: Who Borrows, Where They Borrow, and Why," Pew Charitables Trust Report.

[7] Bracha, A. and S. Meier (2015), "Nudging Credit Scores in the Field: The Effect of Text Reminders on Creditworthiness in the United States," Federal Reserve Bank of Boston, WP 15-02.

[8] Breza, E. and A.G. Chandrasekhar (2015), "Social Networks, Reputation and Commitment: Evidence from a Savings Monitors Experiment," NBER WP No. 21169.

[9] Calvet, L.E., J.Y. Campbell, and P. Sodini (2007), "Down or Out: Assessing the Welfare Costs of Household Investment Mistakes," Journal of Political Economy, 115(5), 707-747.

[10] Campbell, J. (2006), "Household Finance," Journal of Finance, 61(4), 1553-1604.

[11] Card, D. (1999), "The Causal Effect of Education on Earnings," in O. Ashenfelter and D. Card (ed.) Handbook of Labor Economics, vol. 3, 1801-1863, Elsevier.

[12] Coleman-Jensen, A. (2011), "Working for Peanuts: Nonstandard Work and Food Insecurity Across Household Structure," Journal of Family and Economic Issues, 32(1), 84-97.

[13] Coleman-Jensen, A., M. Nord, M. Andrews, and S. Carlson (2011), Household Food Security in the United States in 2010, USDA, Economic Research Service, Economic Research Report No. 125.

[14] Coleman-Jensen, A., C. Gregory, and A. Singh (2014), Houshold Food Security in the United States in 2013, USDA, Economic Research Service, Economic Research Report No. 173. 
[15] Cook, J.T., D.A. Frank, C. Berkowitz, M.M. Black, P.H. Casey, D.B. Cutts, A.F. Meyers, N. Zaldivar, A. Skalicky, S. Levenson, T. Heeren, and M. Nord (2004), "Food insecurity is associated with adverse health outcomes among human infants and toddlers," Journal of Nutrition, 134, 1348-1432

[16] Cook, J.T., D.A. Frank, S.M. Levenson, N.B. Neault, T.C. Heeren, M.M. Black, C. Berkowitz, P.H. Casey, A.F. Meyers, D.B. Cutts, and M. Chilton (2006), "Child Food Insecurity Increases Risks Posed by Household Food Insecurity to Young Children's Health,". Journal of Nutrition, 136, 1073-1076.

[17] Dahl, M., T. DeLeire, and S. Mok (2014), "Food Insufficiency and Income Volatility in US Households: The Effects of Imputed Income in the Survey of Income and Program Participation," Applied Economic Perspectives and Policy, 36(3), 416-437.

[18] Delavande, A., S. Rohwedder, and R. Willis (2008), "Preperation for Retirement, Financial Literacy, and Cognitive Resources," University of Michigan Retirement Research Center Working Paper 2008-190.

[19] Eicher-Miller, H.A., A. Mason, C. Weaver, G. McCabe, and C. Boushey (2009), "Food Insecurity is Associated with Iron Deficiency Anemia in U.S. Adolescents," American Journal of Clinical Nutrition, 90, 1358-1371.

[20] Ernst, K., J. Farris, and U. King (2004), "Quantifying the Economic Cost of Predatory Payday Lending," Durham, NC: Center for Responsible Lending.

[21] Fersterer, J. and R. Winter-Ebmer (2003), "Smoking, Discount Rates, and Returns to Education," Economics of Education Review, 22(6), 561-566.

[22] French, K.R. (2008), "The Cost of Active Investing," Journal of Finance, 63(4), 1537-1573.

[23] Friedman, M. (1957), A Theory of the Consumption Function. Princeton: Princeton Univeristy Press.

[24] Grohmann, A., R. Kouwenberg, and L. Menkhoff (2014), "Roots of Financial Literacy," unpublished manuscript, Leibniz University.

[25] Gundersen, C. (2013), "Food Insecurity is an Ongoing National Concern," Advances in Nutrition, 4, $36-41$.

[26] Gundersen, C., and S.B. Garasky (2012), "Financial Management Skills are Associated with Food Insecurity in a Sample of Households with Children in the United States," Journal of Nutrition, 142, 1865-1870.

[27] Gundersen, C, and J. Gruber (2001), "The Dynamic Determinants of Food Insufficiency," in Second Food Security Measurement and Research Conference, Volume II: Papers, 92-110, USDA, ERS Food Assistance and Nutrition Research Report 11-2. 
[28] Gundersen, C., B. Kreider, and J. Pepper (2011), "The Economics of Food Insecurity in the United States," Applied Economic Perspectives and Policy, 33, 281-303.

[29] Guo, B. (2011), "Household Assets and Food Security: Evidence from the Survey of Program Dynamics," Journal of Family and Economic Issues, 32, 98-110.

[30] Horrace, W.C. and R.L. Oaxaca (2006), "Results on the bias and inconsistency of ordinary least squares for the linear probability model," Economics Letters, 90, 321-327.

[31] Howard, L.L. (2011), "Does Food Insecurity at Home Affect Non-Cognitive Performance at School? A Longitudinal Analysis of Elementary Student Classroom Behavior," Economics of Education Review, 30, 157-176.

[32] Japelli, T. and M. Padula (2013), "Investment in Financial Literacy and Saving Decisions," Journal of Banking and Finance, 37(8), 2779-2792.

[33] Karlan, D., M. McConnell, S. Mullainathan, and J. Zinman (2010), "Getting to the Top of Mind: How Reminders Increase Saving," NBER WP No. 16205.

[34] Kast, F., S. Meier, and D. Pomeranz (2012), "Under-Savers Anonymous: Evidence on Self-Help Groups and Peer Pressure as a Savings Commitment Device," NBER WP No. 18417.

[35] Kirkpatrick, S. and V. Tarasuk (2007), "Food Insecurity is Associated with Nutrient Intakes Among Canadian Adults and Adolescents," Journal of Nutrition, 138, 604-612.

[36] Kirkpatrick, S., L. McIntyre, and M.L. Potestio (2010), "Child Hunger and Long-Term Adverse Consequences for Health," Archives of Pediatrics and Adolescent Medicine, 164, 754-762.

[37] Leete, L. and N. Bania (2010), "The Effect of Income Shocks on Food Insufficiency," Review of Economics of the Household, 8(4), 505-526.

[38] Lusardi, A. and O.S. Mitchell (2008), "Planning and Financial Literacy: How Do Women Fare?" American Economic Review, 98(2), 413-417.

[39] Lusardi, A. and O.S. Mitchell (2009), "How Ordinary Consumers Make Complex Economic Decissions: Financial Literacy and Retirement Readiness," NBER Working Paper 15130.

[40] Lusardi, A. and O.S. Mitchell (2011a), "Financial Literacy and Planning: Implications for Retirement Well-Being," in O.S. Mitchell and A. Lusardi (eds.) Financial Literacy: Implications for Retirement Security and the Financial Marketplace, Oxford and New York: Oxford University Press, 17-19.

[41] Lusardi, A. and O.S. Mitchell (2011b), "The Outlook for Financial Literacy," in O.S. Mitchell and A. Lusardi (eds.) Financial Literacy: Implications for Retirement Security and the Financial Marketplace, Oxford and New York: Oxford University Press, 1-15. 
[42] Lusardi, A. and O.S. Mitchell (2014), "The Economic Importance of Financial Literacy," Journal of Economic Literature, 52, 5-44.

[43] Lusardi, A. and P. Tufano (2009), "Debt Literacy, Financial Experiences, and Overindebtedness," NBER Working Paper 14808.

[44] Lusardi, A., O.S. Mitchell, and V. Curto (2010), "Financial Literacy among the Young," Journal of Consumer Affairs, 44(2), 358-380.

[45] Lusardi, A., O.S. Mitchell, and V. Curto (2014), "Financial Literacy and Financial Sophistication in the Older Population," Journal of Pension Economics and Finance, 13(4), 347-366.

[46] Lusardi, A., P. Michaud, and O.S. Mitchell (2011), "Optimal Financial Literacy and Saving for Retirement," Wharton School Pension Research Council Working Paper 2011-20.

[47] Lusardi, A., P. Michaud, and O.S. Mitchell (2013), "Optimal Financial Knowledge and Wealth Inequality," NBER Working Paper 18669.

[48] Mandell, L. (2008), "Financial Literacy of High School Students," in J.J. Xiao (ed.) Handbook of Consumer Finance Research, New York: Springer New York, 163-183

[49] McIntyre, L., T. Glanville, K. Raine, J. Dayle, B. Anderson, and N. Battaglia (2003), "Do Low-Income Lone Mothers Compromise Their Nutrition to Feed Their Children?" Canadian Medical Association Journal, 168, 686-691.

[50] Ribar, D. and K. Hamrick. (2003), "Dynamics of Poverty and Food Sufficiency," USDA, Economic Research Service, Food Assistance and Nutrition Research Report No. 33.

[51] Seligman, J.E., B. Laraia, and M. Kushel (2010), "Food Insecurity is Associated with Chronic Disease Among Low Income NHANES Paricipants," Journal of Nutrition, 140, 304-310.

[52] Smith, M.M. and C.C. Hevener (2010), "Subprime Lending Over Time: The Role of Race," Community Affairs Department, Federal Reserve Bank of Philadelphia, October.

[53] Stuff, J.E., P. Casey, K. Szeto, J. Gossett, J. Robbins, P. Simpson, C. Connell, and M.L. Bogle (2004), "Household Food Insecurity is Associated with Adult Health Status," Journal of Nutrition, 134, 23302335.

[54] Texas Hunger Initiative (2011), Hunger by the Numbers: A Blueprint for Ending Hunger in Texas, September. http://www . baylor . edu/texashunger/index . php?id=85447.

[55] Whitaker, R.C., S. Phillips, and S. Orzol (2006), "Food Insecurity and the Risks of Depression and Anxiety in Mothers and Behavior Problems in their Preschool-Aged Children," Pediatrics, 118, 859868. 
[56] Ziliak, J., C. Gundersen, and M. Haist (2008), "The Causes, Consequences, and Future of Senior Hunger in America," Special Report by the University of Kentucky Center for Poverty Research for the Meals on Wheels Association of America Foundation. 
Table 1. Descriptive Statistics

\begin{tabular}{|c|c|c|c|c|c|}
\hline Variables & $\mathbf{N}$ & Mean & SD & Minimum & Maximum \\
\hline \multicolumn{6}{|l|}{ Outcomes } \\
\hline Food Security, Food Insecure (1 = yes) & 1009 & 0.826 & 0.380 & 0 & 1 \\
\hline Food Security, Low $(1=$ yes $)$ & 1009 & 0.365 & 0.482 & 0 & 1 \\
\hline Food Security, Very Low (1 = yes) & 1009 & 0.461 & 0.499 & 0 & 1 \\
\hline \multicolumn{6}{|l|}{ Financial Literacy } \\
\hline Index & 988 & 0.000 & 1.000 & -4.050 & 2.325 \\
\hline \multicolumn{6}{|l|}{ Instruments } \\
\hline Parents' Financial Confidence (1 = not at all, 5 = very) & 856 & 3.603 & 1.378 & 1 & 5 \\
\hline HH Smoking, Cigarettes Per Day & 986 & 5.216 & 10.249 & 0 & 90 \\
\hline Discount Rate & 998 & 156.037 & 101.174 & 25 & 275 \\
\hline \multicolumn{6}{|l|}{ Covariates } \\
\hline Age (years) & 994 & 47.764 & 14.281 & 16 & 86 \\
\hline Gender (1 = male) & 1009 & 0.208 & 0.406 & 0 & 1 \\
\hline White $(1=$ yes $)$ & 1009 & 0.286 & 0.452 & 0 & 1 \\
\hline Black (1 = yes) & 1009 & 0.383 & 0.486 & 0 & 1 \\
\hline Hispanic $(1$ = yes $)$ & 1009 & 0.274 & 0.446 & 0 & 1 \\
\hline Other Race $(1=$ yes $)$ & 1009 & 0.032 & 0.175 & 0 & 1 \\
\hline US Born $(1=$ yes $)$ & 1008 & 0.777 & 0.417 & 0 & 1 \\
\hline Education (1 = No High School) & 1009 & 0.102 & 0.303 & 0 & 1 \\
\hline Education (1 = Some High School) & 1009 & 0.195 & 0.397 & 0 & 1 \\
\hline Education (1 = High School Degree) & 1009 & 0.346 & 0.476 & 0 & 1 \\
\hline Education ( 1 = Some College $)$ & 1009 & 0.189 & 0.392 & 0 & 1 \\
\hline $\begin{array}{l}\text { Education (1 = Post-Secondary, Non-degree Award } \\
\text { or Associate's Degree) }\end{array}$ & 1009 & 0.101 & 0.302 & 0 & 1 \\
\hline Education (1 = Bachelor's Degree or More) & 1009 & 0.057 & 0.233 & 0 & 1 \\
\hline Married $(1$ = yes $)$ & 1009 & 0.321 & 0.467 & 0 & 1 \\
\hline Divorced (1 = yes) & 1009 & 0.225 & 0.418 & 0 & 1 \\
\hline Separated $(1$ = yes $)$ & 1009 & 0.096 & 0.295 & 0 & 1 \\
\hline Widowed $(1$ = yes $)$ & 1009 & 0.093 & 0.291 & 0 & 1 \\
\hline Primary Language (1 = English) & 1009 & 0.772 & 0.420 & 0 & 1 \\
\hline Total HH Size & 991 & 3.162 & 2.029 & 1 & 17 \\
\hline Total HH Size Under 18 Years Old & 983 & 1.271 & 1.591 & 0 & 10 \\
\hline HH Income, Past Month, < \$200 (1 = yes) & 1009 & 0.071 & 0.258 & 0 & 1 \\
\hline HH Income, Past Month, \$200-399 (1 = yes) & 1009 & 0.047 & 0.211 & 0 & 1 \\
\hline HH Income, Past Month, \$400-599 (1 = yes) & 1009 & 0.056 & 0.231 & 0 & 1 \\
\hline HH Income, Past Month, \$600-799 (1 = yes) & 1009 & 0.178 & 0.383 & 0 & 1 \\
\hline HH Income, Past Month, \$800-999 (1 = yes) & 1009 & 0.106 & 0.308 & 0 & 1 \\
\hline HH Income, Past Month, \$1000-1249 (1 = yes) & 1009 & 0.172 & 0.378 & 0 & 1 \\
\hline HH Income, Past Month, \$1250-1499 (1 = yes) & 1009 & 0.126 & 0.332 & 0 & 1 \\
\hline HH Income, Past Month, \$1500-1999 (1 = yes) & 1009 & 0.121 & 0.326 & 0 & 1 \\
\hline HH Income, Past Month, Missing ( 1 = yes $)$ & 1009 & 0.042 & 0.200 & 0 & 1 \\
\hline HH Debt, Total, $<\$ 200(1=$ yes $)$ & 1009 & 0.283 & 0.451 & 0 & 1 \\
\hline HH Debt, Total, \$200-999 (1 = yes) & 1009 & 0.089 & 0.285 & 0 & 1 \\
\hline HH Debt, Total, \$1000-1999 (1 = yes) & 1009 & 0.083 & 0.276 & 0 & 1 \\
\hline HH Debt, Total, \$2000-4999 (1 = yes) & 1009 & 0.133 & 0.340 & 0 & 1 \\
\hline HH Debt, Total, \$5000-9999 (1 = yes) & 1009 & 0.101 & 0.302 & 0 & 1 \\
\hline HH Debt, Total, $\$ 10000-19999$ (1 = yes) & 1009 & 0.084 & 0.278 & 0 & 1 \\
\hline HH Debt, Total, Missing ( 1 = yes) & 1009 & 0.078 & 0.269 & 0 & 1 \\
\hline HH Assets, Total, $<\$ 50$ (1 = yes) & 1009 & 0.725 & 0.446 & 0 & 1 \\
\hline HH Assets, Total, $\$ 50-99(1=$ yes $)$ & 1009 & 0.060 & 0.238 & 0 & 1 \\
\hline HH Assets, Total, $>\$ 100(1=$ yes $)$ & 1009 & 0.048 & 0.213 & 0 & 1 \\
\hline HH Income, Past Month Relative to "Typical" (1 = worse) & 1009 & 0.282 & 0.450 & 0 & 1 \\
\hline HH Income, Past Month Relative to "Typical" (1 = same) & 1009 & 0.606 & 0.489 & 0 & 1 \\
\hline HH Income, Past Month Relative to "Typical", Missing ( 1 = yes) & 1009 & 0.013 & 0.113 & 0 & 1 \\
\hline HH Food Source, Super Store $(1=$ yes $)$ & 1009 & 0.722 & 0.448 & 0 & 1 \\
\hline HH Food Source, Grocery Store (1 = yes) & 1009 & 0.774 & 0.418 & 0 & 1 \\
\hline HH Food Source, Covenient Store $(1$ = yes) & 1009 & 0.105 & 0.307 & 0 & 1 \\
\hline HH Food Source, Neighborhood Store (1 = yes) & 1009 & 0.159 & 0.365 & 0 & 1 \\
\hline HH Food Source, Garden $(1$ = yes $)$ & 1009 & 0.029 & 0.167 & 0 & 1 \\
\hline HH Food Source, Religious Center ( 1 = yes) & 1009 & 0.081 & 0.273 & 0 & 1 \\
\hline HH Food Source, Pantry/Charity $(1$ = yes $)$ & 1009 & 0.817 & 0.387 & 0 & 1 \\
\hline HH Food Source, Family (1 = yes) & 1009 & 0.076 & 0.266 & 0 & 1 \\
\hline HH Food Source, Friends/Neighbors ( 1 = yes) & 1009 & 0.044 & 0.204 & 0 & 1 \\
\hline
\end{tabular}

Notes: $\mathrm{HH}=$ household. 
Table 2. Marginal Effects for Financial Literacy on Food Insecurity

\begin{tabular}{|c|c|c|c|c|c|c|c|c|c|c|c|c|}
\hline & \multicolumn{3}{|c|}{ (1) } & \multicolumn{3}{|c|}{$(2)$} & \multicolumn{3}{|c|}{$(3)$} & \multicolumn{3}{|c|}{$(4)$} \\
\hline & OLS & GMM & IV Probit & OLS & GMM & IV Probit & OLS & GMM & IV Probit & OLS & GMM & IV Probit \\
\hline Financial Literacy & $\begin{array}{c}-0.030 \dagger \\
(0.013)\end{array}$ & $\begin{array}{c}-0.180 * \\
(0.059)\end{array}$ & $\begin{array}{c}-0.178 * \\
(0.045)\end{array}$ & $\begin{array}{c}-0.016 \\
(0.015)\end{array}$ & $\begin{array}{c}-0.186 \dagger \\
(0.076)\end{array}$ & $\begin{array}{c}-0.185^{*} \\
(0.059)\end{array}$ & $\begin{array}{c}-0.016 \\
(0.015)\end{array}$ & $\begin{array}{c}-0.163 \dagger \\
(0.072)\end{array}$ & $\begin{array}{c}-0.167 * \\
(0.061)\end{array}$ & $\begin{array}{c}-0.018 \\
(0.015)\end{array}$ & $\begin{array}{c}-0.182 \dagger \\
(0.078)\end{array}$ & $\begin{array}{c}-0.179 * \\
(0.062)\end{array}$ \\
\hline HH \& Indivdual Controls & no & no & no & yes & yes & yes & yes & yes & yes & yes & yes & yes \\
\hline Food Source Controls & no & no & no & no & no & no & yes & yes & yes & yes & yes & yes \\
\hline Zip Code Fixed Effects & no & no & no & no & no & no & no & no & no & yes & yes & yes \\
\hline Under Identification (p-value) & - & 0.000 & - & - & 0.000 & - & - & 0.000 & - & - & 0.000 & - \\
\hline Over Identification (p-value) & - & 0.326 & - & - & 0.523 & - & - & 0.515 & - & - & 0.719 & - \\
\hline Endogeneity (p-value) & - & 0.001 & - & - & 0.008 & - & - & 0.020 & - & - & 0.018 & - \\
\hline Kleibergen-Paap (robust F-Stat) & - & 27.31 & - & - & 16.30 & - & - & 17.55 & - & - & 16.23 & - \\
\hline Anderson-Rubin (p-value) & - & 0.001 & - & - & 0.016 & - & - & 0.037 & - & - & 0.036 & - \\
\hline Observations & 988 & 817 & 817 & 942 & 777 & 777 & 942 & 777 & 777 & 942 & 777 & 777 \\
\hline
\end{tabular}

Notes: Dependent variable is one if household is food insecure, zero otherwise. Exclusion restrictions include the respondent's perception of parental confidence as it relates to financial matters and the number of cigarettes smoked daiy; average marginal effects reported for IV probit model; robust standard errors in parenthesis; $\ddagger \mathrm{p}<0.10$, $\dagger \mathrm{p}<$ 0.05 , and ${ }^{*} \mathrm{p}<0.01$.

Table 3. Marginal Effects for Financial Literacy on Very Low Levels of Food Security

\begin{tabular}{|c|c|c|c|c|c|c|c|c|c|c|c|c|}
\hline & \multicolumn{3}{|c|}{ (1) } & \multicolumn{3}{|c|}{ (2) } & \multicolumn{3}{|c|}{ (3) } & \multicolumn{3}{|c|}{ (4) } \\
\hline & OLS & GMM & IV Probit & OLS & GMM & IV Probit & OLS & GMM & IV Probit & OLS & GMM & IV Probit \\
\hline Financial Literacy & $\begin{array}{c}-0.010 \\
(0.016)\end{array}$ & $\begin{array}{c}-0.180 \dagger \\
(0.077)\end{array}$ & $\begin{array}{l}-0.161^{*} \\
(0.049)\end{array}$ & $\begin{array}{c}-0.015 \\
(0.018)\end{array}$ & $\begin{array}{c}-0.264 \dagger \\
(0.103)\end{array}$ & $\begin{array}{c}-0.208 * \\
(0.054)\end{array}$ & $\begin{array}{c}-0.012 \\
(0.018)\end{array}$ & $\begin{array}{c}-0.243 \dagger \\
(0.099)\end{array}$ & $\begin{array}{c}-0.196 * \\
(0.057)\end{array}$ & $\begin{array}{c}-0.012 \\
(0.019)\end{array}$ & $\begin{array}{c}-0.253 \dagger \\
(0.106)\end{array}$ & $\begin{array}{c}-0.206 * \\
(0.060)\end{array}$ \\
\hline HH \& Indivdual Controls & no & no & no & yes & yes & yes & yes & yes & yes & yes & yes & yes \\
\hline Food Source Controls & no & no & no & no & no & no & yes & yes & yes & yes & yes & yes \\
\hline Zip Code Fixed Effects & no & no & no & no & no & no & no & no & no & yes & yes & yes \\
\hline Under Identification (p-value) & - & 0.000 & - & - & 0.000 & - & - & 0.000 & - & - & 0.000 & - \\
\hline Over Identification (p-value) & - & 0.124 & - & - & 0.760 & - & - & 0.815 & - & - & 0.616 & - \\
\hline Endogeneity (p-value) & - & 0.011 & - & - & 0.007 & - & - & 0.009 & - & - & 0.011 & - \\
\hline Kleibergen-Paap (robust F-Stat) & - & 27.31 & - & - & 16.30 & - & - & 17.55 & - & - & 16.23 & - \\
\hline Anderson-Rubin (p-value) & - & 0.011 & - & - & 0.015 & - & - & 0.025 & - & - & 0.026 & - \\
\hline Observations & 988 & 817 & 817 & 942 & 777 & 777 & 942 & 777 & 777 & 942 & 777 & 777 \\
\hline
\end{tabular}

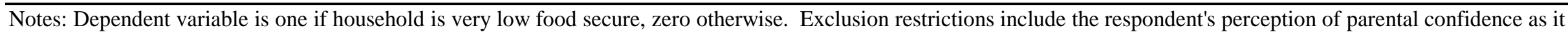

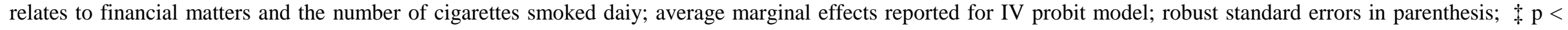
0.10 , $\dagger \mathrm{p}<0.05$, and $* \mathrm{p}<0.01$. 


\section{A Data Appendix}

\section{A.1 Sample Selection Process}

A stratified probabilistic survey design was used. A list of 172 NTFB-affiliated pantries was divided into two strata: urban and rural. Urban versus rural pantries were determined by their distance from Southern Methodist University, which is approximately five miles from downtown Dallas. Urban pantries are those roughly less than 40 miles away or located in Denton County (as this is also an urban area). The remaining pantries were deemed to be rural. This resulted in a classification of 130 "urban" pantries and 42 "rural" pantries. To reach a sample of 1,000 surveys in total, it was determined that we would randomly select 42 pantries and collect 24 surveys from each location $(42 * 24=1,008)$. To ensure that our sample would be representative of the urban/rural split in the population, we determined that $76 \%$ of the pantries in our sample should be urban (130/172) and the remaining $24 \%(42 / 172)$ rural. Thus, of the 42 pantries to be sampled, 31 urban pantries and 11 rural pantries would be chosen.

Using equal-probability distributions for each strata, pantries were chosen with replacement which resulted in three urban pantries being selected twice and one rural pantry being selected twice. Hence, we ended up with 38 unique pantries to survey; 24 surveys from 34 pantries and 48 from four pantries. The intended sample size was 1,008. However, four pantries chosen either refused to participate or had been closed by the time we were ready to visit. Thus, four alternate pantries were chosen based on similar location and size to the original four pantries. One of the alternate choices also did not turn out as a viable option; an additional alternative was added. 


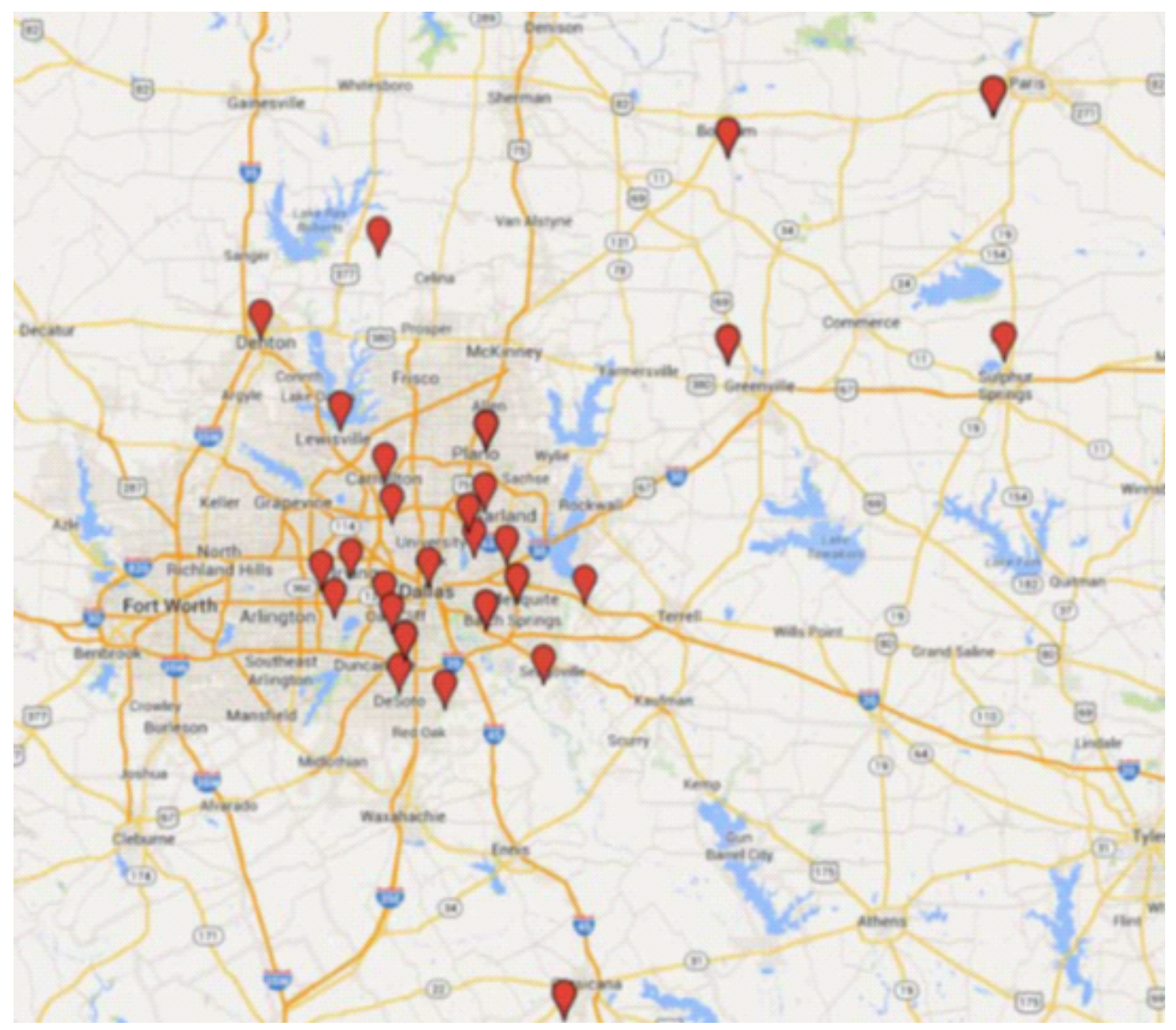

Figure A1. Map of Food Pantries Included in Sample.

In the end, we administered the survey across 38 pantries, although the pantries included deviated from our initial design. Figure 1 indicates the locations of these 38 pantries throughout North Texas. Moreover, the actual number of surveys collected from the pantries deviated slightly from the intended numbers. The final sample includes 24 respondents from 33 pantries, 25 respondents from one pantry, 47 respondents from one pantry, 48 respondents from two pantries, and 49 respondents from one pantry. The final sample size is 1,009 .

After the sample of pantries was settled, a pilot survey was conducted to test the survey instrument and train the survey staff. Ninety respondents were interviewed from five different pantries; the data are not included in the final database. Both English and bilingual interviewers visited each pantry allowing the team to capture clients who were both English and Spanish speaking only. Of the 1,009 surveys administered, 197 were given in Spanish. Surveyors randomly select food pantry customers at each pantry and avoided interviewing people from the same family and address. The surveys were administered between March and September 2014. The survey respondents each received a $\$ 20$ Wal-Mart gift card for their cooperation and willingness to participate in the survey. 


\section{A.2 Survey Administration}

After the sample of pantries was settled, a pilot survey was conducted to test the survey instrument and train the survey staff. Ninety respondents were interviewed from five different pantries; the data are not included in the final database. The pilot survey allowed the staff to identify ambiguities with specific survey questions, flush out potential inconsistencies with regard to question comprehension, and also train the staff in proper etiquette, sensitivity, and overall protocol when conducting interviews. Once the pilot study was complete, the survey was redesigned accordingly and the study commenced.

Using an online scheduling system, the 38 food pantries were contacted and scheduled and the interview team signed up in groups of 1-4 to visit pantries to conduct surveys. The interview team consisted of graduate and undergraduate anthropologists and sociologists from Southern Methodist University, University of North Texas, and University of Texas at Dallas. Both English and bilingual interviewers visited each pantry allowing the team to capture clients who were both English and Spanish speaking only. Of the 1,009 surveys administered, 197 were given in Spanish.

The team sought to randomly select food pantry customers at each pantry and avoided interviewing people from the same family and address. The team found that the operation and organization of each pantry varied and therefore made adjustments to accommodate each unique situation while maintaining the overall objectives of the study. The survey respondents each received a $\$ 20$ Wal-Mart gift card for their cooperation and willingness to participate in the survey.

\section{A.3 Financial Literacy Questions}


Traditional ‘Big Five’ (eliminated two questions after pilot testing, adding Q13 from RAND ALP \#64)

1. Suppose you had $\$ 100$ in a savings account and the interest rate was 2 percent per year. After 5 years, how much do you think you would have in the account if you left the money to grow?

[ ] More than $\$ 102$

[ ] Exactly $\$ 102$

[ ] Less than $\$ 102$

[] DK

2. Imagine that the interest rate on your savings account was 1 percent per year and inflation was 2 percent per year. After 1 year, would you be able to buy more than, exactly the same as, or less than today with the money in this account?
[ ] More than today
[ ] Exactly the same as today
[ ] Less than today
[ ] DK

3. Suppose that 12 months from now, your household income has doubled and the prices of all goods have doubled too. How much will your household be able to buy with your income?
[] More than today
[ ] Exactly the same as today
[ ] Less than today
[] DK

READ: The next set of questions require a “True” or "False” answer.

4. Do you think that the following statement is true or false? "A 15-year mortgage typically requires higher monthly payments than a 30-year mortgage, but the total interest paid over the life of the loan will be less.”
[ ] True
[ ] False
[] DK

NEFE Financial Evaluation Toolkit (Plus additional questions in \#13 from Gundersen \& Garasky 2012 and wording in \#11-12 from FINRA 2012 Report)

5. Fixed expenses are set amounts that must be paid on a regular basis.
[ ] True
[ ] False
[ ] DK

6. Net pay is after all of the taxes and other withholdings have been taken from gross pay.
[] True
[ ] False
[ ] DK

7. The way interest, or the monthly finance charge, is calculated is the same for all credit cards.
[ ] True
[ ] False
[] DK

8. Compound interest is when only the amount of money deposited earns interest.
[ ] True
[ ] False
[ ] DK

9. Generally credit card companies and other lenders only let a person borrow the amount of money that they will easily be able to repay.
[ ] True
[ ] False
[ ] DK

10. Credit reports contain information about current credit accounts and loans as well as past accounts that are now closed.
[ ] True
[ ] False
[ ] DK 
11. Thinking back to when you were a child, how confident (were/was) your (parents/parent/guardian) in dealing with day-to-day financial matters, such as checking accounts, credit and debit cards and tracking expenses?

\begin{tabular}{|c|c|c|c|c|c|}
\hline Don't Know & Not Confident & $\begin{array}{c}\text { A Little } \\
\text { Confident }\end{array}$ & $\begin{array}{c}\text { Somewhat } \\
\text { Confident }\end{array}$ & Confident & $\begin{array}{c}\text { Very } \\
\text { Confident }\end{array}$ \\
\hline 0 & 1 & 2 & 3 & 4 & 5 \\
\hline
\end{tabular}

12. Today, how confident are you in dealing with day-to-day financial matters, such as checking accounts, credit and debit cards and tracking expenses?

\begin{tabular}{|c|c|c|c|c|}
\hline Not Confident & $\begin{array}{c}\text { A Little } \\
\text { Confident }\end{array}$ & $\begin{array}{c}\text { Somewhat } \\
\text { Confident }\end{array}$ & Confident & $\begin{array}{c}\text { Very } \\
\text { Confident }\end{array}$ \\
\hline 1 & 2 & 3 & 4 & 5 \\
\hline
\end{tabular}

13. For each financial practice, please circle the number that best describes your current behavior.

\begin{tabular}{|c|c|c|c|c|c|c|}
\hline Financial Practice & $\begin{array}{l}\text { I do not } \\
\text { have the means } \\
\text { to do this }\end{array}$ & $\begin{array}{l}\text { I am not } \\
\text { considering } \\
\text { this }\end{array}$ & $\begin{array}{c}\text { I am } \\
\text { considering } \\
\text { this }\end{array}$ & $\begin{array}{l}\text { I am doing } \\
\text { this sometimes }\end{array}$ & $\begin{array}{l}\text { I am doing } \\
\text { this most } \\
\text { of the time }\end{array}$ & $\begin{array}{l}\text { I am doing } \\
\text { this all } \\
\text { of the time }\end{array}$ \\
\hline $\begin{array}{l}\text { 13A. Setting personal financial } \\
\text { goals for the year. }\end{array}$ & 0 & 1 & 2 & 3 & 4 & 5 \\
\hline $\begin{array}{l}\text { 13B. Using a spending plan or } \\
\text { budget. }\end{array}$ & 0 & 1 & 2 & 3 & 4 & 5 \\
\hline $\begin{array}{l}\text { 13C. Keeping track of } \\
\text { spending. }\end{array}$ & 0 & 1 & 2 & 3 & 4 & 5 \\
\hline $\begin{array}{l}\text { 13D. Reviewing your } \\
\text { bills for accuracy. }\end{array}$ & 0 & 1 & 2 & 3 & 4 & 5 \\
\hline $\begin{array}{l}\text { 13E. Paying bills on time } \\
\text { each month. }\end{array}$ & 0 & 1 & 2 & 3 & 4 & 5 \\
\hline $\begin{array}{l}\text { 13F. Paying bills using a } \\
\text { checking account. }\end{array}$ & 0 & 1 & 2 & 3 & 4 & 5 \\
\hline $\begin{array}{l}\text { 13G. Finding ways to } \\
\text { decrease expenses. }\end{array}$ & 0 & 1 & 2 & 3 & 4 & 5 \\
\hline $\begin{array}{l}\text { 13H. Reviewing income and } \\
\text { expenses before making } \\
\text { large purchases. }\end{array}$ & 0 & 1 & 2 & 3 & 4 & 5 \\
\hline
\end{tabular}


14. Please circle the number that best describes your level of agreement with each of the following statements.

\begin{tabular}{|l|c|c|c|c|c|}
\hline Statement: & $\begin{array}{c}\text { Strongly } \\
\text { Disagree }\end{array}$ & Disagree & Undecided & Agree & $\begin{array}{c}\text { Strongly } \\
\text { Agree }\end{array}$ \\
\hline $\begin{array}{l}\text { 14A. Saving money regularly is } \\
\text { important to me. }\end{array}$ & 1 & 2 & 3 & 4 & 5 \\
\hline $\begin{array}{l}\text { 14B. Keeping track of spending is a } \\
\text { good habit. }\end{array}$ & 1 & 2 & 3 & 4 & 5 \\
\hline $\begin{array}{l}\text { 14C. Planning my personal budget is a } \\
\text { priority. }\end{array}$ & 1 & 2 & 3 & 4 & 5 \\
\hline $\begin{array}{l}\text { 14D. Starting an emergency savings fund } \\
\text { is important to me. }\end{array}$ & 1 & 2 & 3 & 4 & 5 \\
\hline
\end{tabular}


A.4 Additional Results 
Table A1. Marginal Effects for Financial Literacy on Food Insecurity

\begin{tabular}{|c|c|c|c|c|c|c|c|c|c|c|c|c|}
\hline & \multicolumn{3}{|c|}{ (1) } & \multicolumn{3}{|c|}{ (2) } & \multicolumn{3}{|c|}{ (3) } & \multicolumn{3}{|c|}{ (4) } \\
\hline & OLS & GMM & IV Probit & OLS & GMM & IV Probit & OLS & GMM & IV Probit & OLS & GMM & IV Probi \\
\hline Financial Literacy & $\begin{array}{c}-0.030 \dagger \\
(0.013)\end{array}$ & $\begin{array}{l}-0.163 * \\
(0.057)\end{array}$ & $\begin{array}{c}-0.157^{*} \\
(0.048)\end{array}$ & $\begin{array}{c}-0.016 \\
(0.015)\end{array}$ & $\begin{array}{c}-0.167 \dagger \\
(0.077)\end{array}$ & $\begin{array}{c}-0.158 \dagger \\
(0.065)\end{array}$ & $\begin{array}{c}-0.016 \\
(0.015)\end{array}$ & $\begin{array}{l}-0.143 \ddagger \\
(0.074)\end{array}$ & $\begin{array}{c}-0.140 \dagger \\
(0.066)\end{array}$ & $\begin{array}{c}-0.018 \\
(0.015)\end{array}$ & $\begin{array}{c}-0.167 \dagger \\
(0.082)\end{array}$ & $\begin{array}{c}-0.159 \dagger \\
(0.067)\end{array}$ \\
\hline HH \& Indivdual Controls & no & no & no & yes & yes & yes & yes & yes & yes & yes & yes & yes \\
\hline Food Source Controls & no & no & no & no & no & no & yes & yes & yes & yes & yes & yes \\
\hline Zip Code Fixed Effects & no & no & no & no & no & no & no & no & no & yes & yes & yes \\
\hline Under Identification (p-value) & - & 0.000 & - & - & 0.000 & - & - & 0.000 & - & - & 0.000 & - \\
\hline Over Identification (p-value) & - & - & - & - & - & - & - & - & - & - & - & - \\
\hline Endogeneity (p-value) & - & 0.006 & - & - & 0.037 & - & - & 0.074 & - & - & 0.055 & - \\
\hline Kleibergen-Paap (robust F-Stat) & - & 51.40 & - & - & 28.63 & - & - & 30.39 & - & - & 27.24 & - \\
\hline Anderson-Rubin (p-value) & - & 0.002 & - & - & 0.019 & - & - & 0.040 & - & - & 0.028 & - \\
\hline Observations & 988 & 839 & 839 & 942 & 799 & 799 & 942 & 799 & 799 & 942 & 799 & 799 \\
\hline
\end{tabular}

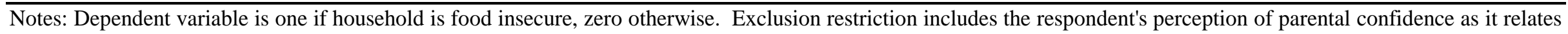
to financial matters; average marginal effects reported for IV probit model; robust standard errors in parenthesis; $\ddagger \mathrm{p}<0.10$, $† \mathrm{p}<0.05$, and $* \mathrm{p}<0.01$.

Table A2. Marginal Effects for Financial Literacy on Very Low Levels of Food Security

\begin{tabular}{|c|c|c|c|c|c|c|c|c|c|c|c|c|}
\hline & \multicolumn{3}{|c|}{ (1) } & \multicolumn{3}{|c|}{$(2)$} & \multicolumn{3}{|c|}{ (3) } & \multicolumn{3}{|c|}{ (4) } \\
\hline & OLS & GMM & IV Probit & OLS & GMM & IV Probit & OLS & GMM & IV Probit & OLS & GMM & IV Probi \\
\hline Financial Literacy & $\begin{array}{c}-0.010 \\
(0.016)\end{array}$ & $\begin{array}{c}-0.144 \ddagger \\
(0.076)\end{array}$ & $\begin{array}{c}-0.129 \dagger \\
(0.055)\end{array}$ & $\begin{array}{c}-0.015 \\
(0.018)\end{array}$ & $\begin{array}{c}-0.275 \dagger \\
(0.108)\end{array}$ & $\begin{array}{c}-0.215^{*} \\
(0.052)\end{array}$ & $\begin{array}{c}-0.012 \\
(0.018)\end{array}$ & $\begin{array}{c}-0.252 \dagger \\
(0.104)\end{array}$ & $\begin{array}{c}-0.203^{*} \\
(0.056)\end{array}$ & $\begin{array}{c}-0.012 \\
(0.019)\end{array}$ & $\begin{array}{c}-0.264 \dagger \\
(0.111)\end{array}$ & $\begin{array}{c}0.212 * \\
(0.058)\end{array}$ \\
\hline HH \& Indivdual Controls & no & no & no & yes & yes & yes & yes & yes & yes & yes & yes & yes \\
\hline Food Source Controls & no & no & no & no & no & no & yes & yes & yes & yes & yes & yes \\
\hline Zip Code Fixed Effects & no & no & no & no & no & no & no & no & no & yes & yes & yes \\
\hline Under Identification (p-value) & - & 0.000 & - & - & 0.000 & - & - & 0.000 & - & - & 0.000 & - \\
\hline Over Identification (p-value) & - & - & - & - & - & - & - & - & - & - & - & - \\
\hline Endogeneity (p-value) & - & 0.047 & - & - & 0.006 & - & - & 0.008 & - & - & 0.010 & - \\
\hline Kleibergen-Paap (robust F-Stat) & - & 51.40 & - & - & 28.63 & - & - & 30.39 & - & - & 27.24 & - \\
\hline Anderson-Rubin (p-value) & - & 0.046 & - & - & 0.004 & - & - & 0.007 & - & - & 0.009 & - \\
\hline Observations & 988 & 839 & 839 & 942 & 799 & 799 & 942 & 799 & 799 & 942 & 799 & 799 \\
\hline
\end{tabular}

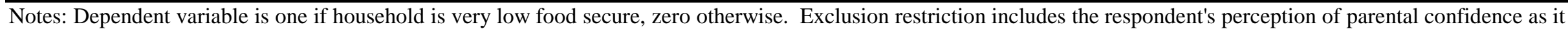
relates to financial matters; average marginal effects reported for IV probit model; robust standard errors in parenthesis; $\ddagger \mathrm{p}<0.10$, $\dagger \mathrm{p}<0.05$, and $* \mathrm{p}<0.01$. 
Table A3. Marginal Effects for Financial Literacy on Food Insecurity

\begin{tabular}{|c|c|c|c|c|c|c|c|c|c|c|c|c|}
\hline & \multicolumn{3}{|c|}{ (1) } & \multicolumn{3}{|c|}{ (2) } & \multicolumn{3}{|c|}{ (3) } & \multicolumn{3}{|c|}{ (4) } \\
\hline & OLS & GMM & IV Probit & OLS & GMM & IV Probit & OLS & GMM & IV Probit & OLS & GMM & IV Probit \\
\hline Financial Literacy & $\begin{array}{c}-0.030 \dagger \\
(0.013)\end{array}$ & $\begin{array}{c}-0.136 * \\
(0.050)\end{array}$ & $\begin{array}{c}-0.140 * \\
(0.050)\end{array}$ & $\begin{array}{c}-0.016 \\
(0.015)\end{array}$ & $\begin{array}{c}-0.133 \dagger \\
(0.066)\end{array}$ & $\begin{array}{c}-0.123 \ddagger \\
(0.073)\end{array}$ & $\begin{array}{c}-0.016 \\
(0.015)\end{array}$ & $\begin{array}{c}-0.116 \ddagger \\
(0.064)\end{array}$ & $\begin{array}{c}-0.111 \\
(0.070)\end{array}$ & $\begin{array}{c}-0.018 \\
(0.015)\end{array}$ & $\begin{array}{c}-0.118 \ddagger \\
(0.068)\end{array}$ & $\begin{array}{c}-0.107 \\
(0.074)\end{array}$ \\
\hline HH \& Indivdual Controls & no & no & no & yes & yes & yes & yes & yes & yes & yes & yes & yes \\
\hline Food Source Controls & no & no & no & no & no & no & yes & yes & yes & yes & yes & yes \\
\hline Zip Code Fixed Effects & no & no & no & no & no & no & no & no & no & yes & yes & yes \\
\hline Under Identification (p-value) & - & 0.000 & - & - & 0.000 & - & - & 0.000 & - & - & 0.000 & - \\
\hline Over Identification (p-value) & - & 0.073 & - & - & 0.086 & - & - & 0.116 & - & - & 0.099 & - \\
\hline Endogeneity (p-value) & - & 0.012 & - & - & 0.059 & - & - & 0.105 & - & - & 0.130 & - \\
\hline Kleibergen-Paap (robust F-Stat) & - & 25.25 & - & - & 13.69 & - & - & 14.63 & - & - & 14.03 & - \\
\hline Anderson-Rubin (p-value) & - & 0.002 & - & - & 0.016 & - & - & 0.040 & - & - & 0.040 & - \\
\hline Observations & 988 & 808 & 808 & 942 & 768 & 768 & 942 & 768 & 768 & 942 & 768 & 768 \\
\hline
\end{tabular}

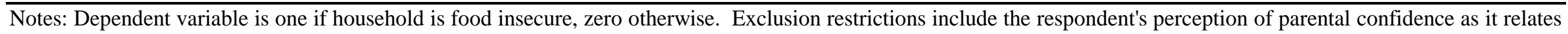

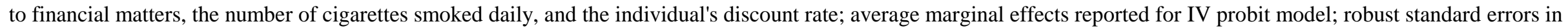
parenthesis; $\ddagger \mathrm{p}<0.10$, $\dagger \mathrm{p}<0.05$, and $* \mathrm{p}<0.01$.

Table A4. Marginal Effects for Financial Literacy on Very Low Levels of Food Security

\begin{tabular}{|c|c|c|c|c|c|c|c|c|c|c|c|c|}
\hline & \multicolumn{3}{|c|}{ (1) } & \multicolumn{3}{|c|}{ (2) } & \multicolumn{3}{|c|}{ (3) } & \multicolumn{3}{|c|}{ (4) } \\
\hline & OLS & GMM & IV Probit & OLS & GMM & IV Probit & OLS & GMM & IV Probit & OLS & GMM & IV Probit \\
\hline Financial Literacy & $\begin{array}{c}-0.010 \\
(0.016)\end{array}$ & $\begin{array}{c}-0.170 \dagger \\
(0.067)\end{array}$ & $\begin{array}{l}-0.155^{*} \\
(0.045)\end{array}$ & $\begin{array}{c}-0.015 \\
(0.018)\end{array}$ & $\begin{array}{c}-0.230 \dagger \\
(0.091)\end{array}$ & $\begin{array}{c}-0.192 * \\
(0.056)\end{array}$ & $\begin{array}{c}-0.012 \\
(0.018)\end{array}$ & $\begin{array}{c}-0.213 \dagger \\
(0.089)\end{array}$ & $\begin{array}{c}-0.180 * \\
(0.059)\end{array}$ & $\begin{array}{c}-0.012 \\
(0.019)\end{array}$ & $\begin{array}{c}-0.207 \dagger \\
(0.092)\end{array}$ & $\begin{array}{l}-0.181 * \\
(0.064)\end{array}$ \\
\hline HH \& Indivdual Controls & no & no & no & yes & yes & yes & yes & yes & yes & yes & yes & yes \\
\hline Food Source Controls & no & no & no & no & no & no & yes & yes & yes & yes & yes & yes \\
\hline Zip Code Fixed Effects & no & no & no & no & no & no & no & no & no & yes & yes & yes \\
\hline Under Identification (p-value) & - & 0.000 & - & - & 0.000 & - & - & 0.000 & - & - & 0.000 & - \\
\hline Over Identification (p-value) & - & 0.270 & - & - & 0.524 & - & - & 0.540 & - & - & 0.456 & - \\
\hline Endogeneity (p-value) & - & 0.007 & - & - & 0.010 & - & - & 0.014 & - & - & 0.022 & - \\
\hline Kleibergen-Paap (robust F-Stat) & - & 25.25 & - & - & 13.69 & - & - & 14.63 & - & - & 14.03 & - \\
\hline Anderson-Rubin (p-value) & - & 0.017 & - & - & 0.027 & - & - & 0.046 & - & - & 0.055 & - \\
\hline Observations & 988 & 808 & 808 & 942 & 768 & 768 & 942 & 768 & 768 & 942 & 768 & 768 \\
\hline
\end{tabular}

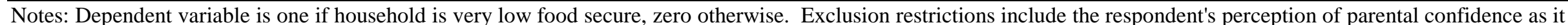

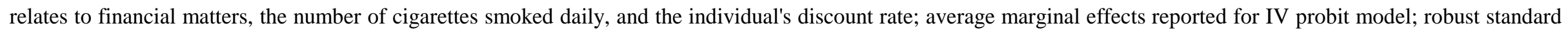
errors in parenthesis; $\ddagger \mathrm{p}<0.10, \dagger \mathrm{p}<0.05$, and ${ }^{*} \mathrm{p}<0.01$. 
Table A5. Marginal Effects for Financial Literacy by Component on Food Insecurity

\begin{tabular}{|c|c|c|c|c|c|c|c|c|c|c|c|c|}
\hline & \multicolumn{3}{|c|}{ Knowledge } & \multicolumn{3}{|c|}{ Beliefs } & \multicolumn{3}{|c|}{ Behaviors } & \multicolumn{3}{|c|}{ Confidence } \\
\hline & OLS & GMM & IV Probit & OLS & GMM & IV Probit & OLS & GMM & IV Probit & OLS & GMM & IV Probit \\
\hline Financial Literacy & $\begin{array}{c}0.015 \\
(0.015)\end{array}$ & $\begin{array}{c}-0.721 \\
(0.716)\end{array}$ & $\begin{array}{c}-0.338^{*} \\
(0.039)\end{array}$ & $\begin{array}{c}0.001 \\
(0.014)\end{array}$ & $\begin{array}{c}-0.45 \\
(0.287)\end{array}$ & $\begin{array}{c}-0.297^{*} \\
(0.050)\end{array}$ & $\begin{array}{c}-0.012 \\
(0.014)\end{array}$ & $\begin{array}{l}-0.268 \dagger \\
(0.128)\end{array}$ & $\begin{array}{c}-0.238^{*} \\
(0.066)\end{array}$ & $\begin{array}{l}-0.037 * \\
(0.012)\end{array}$ & $\begin{array}{l}-0.120 \dagger \\
(0.051)\end{array}$ & $\begin{array}{c}-0.117^{*} \\
(0.049)\end{array}$ \\
\hline
\end{tabular}

HH \& Indivdual Controls yes yes yes yes yes yes yes yes yes yes yes yes yes yes yes yes yes

Food Source Controls yes yes yes yes yes yes yes yes yes yes yes yes yes yes yes yes yes yes yes

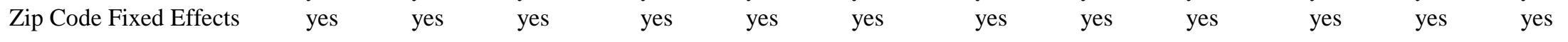

$\begin{array}{llllllllll}\text { Under Identification (p-value) } & - & 0.476 & - & - & 0.110 & - & - & 0.001 & -\end{array}$

$\begin{array}{llllllllll}\text { Over Identification (p-value) } & - & 0.932 & - & - & 0.869 & - & - & - & -\end{array}$

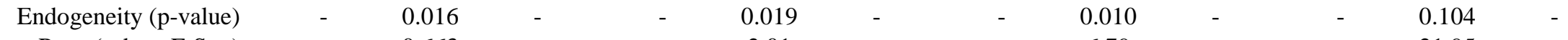

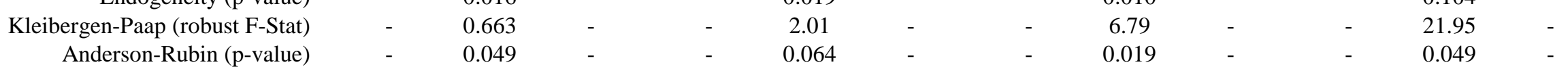

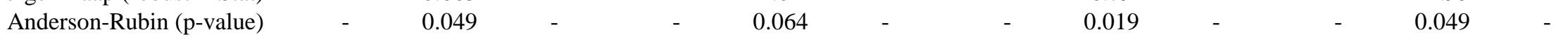

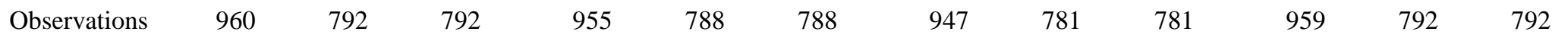

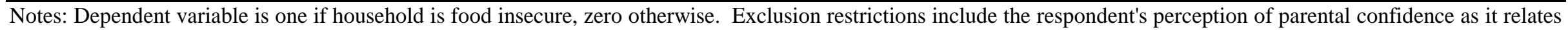

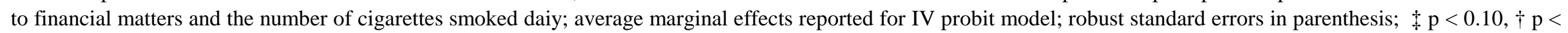
0.05 , and $* p<0.01$.

Table A6. Marginal Effects for Financial Literacy by Component on Very Low Levels of Food Security

\begin{tabular}{|c|c|c|c|c|c|c|c|c|c|c|c|c|}
\hline & \multicolumn{3}{|c|}{ Knowledge } & \multicolumn{3}{|c|}{ Beliefs } & \multicolumn{3}{|c|}{ Behaviors } & \multicolumn{3}{|c|}{ Confidence } \\
\hline & OLS & GMM & IV Probit & OLS & GMM & IV Probit & OLS & GMM & IV Probit & OLS & GMM & IV Probit \\
\hline Financial Literacy & $\begin{array}{c}0.003 \\
(0.019)\end{array}$ & $\begin{array}{l}-1.046 \\
(0.971)\end{array}$ & $\begin{array}{l}-0.338^{*} \\
(0.034)\end{array}$ & $\begin{array}{c}0.009 \\
(0.018)\end{array}$ & $\begin{array}{c}-0.599 \\
(0.398)\end{array}$ & $\begin{array}{c}-0.293^{*} \\
(0.046)\end{array}$ & $\begin{array}{c}0.01 \\
(0.018)\end{array}$ & $\begin{array}{c}-0.347 \dagger \\
(0.168)\end{array}$ & $\begin{array}{l}-0.244^{*} \\
(0.063)\end{array}$ & $\begin{array}{l}-0.054^{*} \\
(0.016)\end{array}$ & $\begin{array}{c}-0.163 \dagger \\
(0.068)\end{array}$ & $\begin{array}{l}-0.151^{*} \\
(0.050)\end{array}$ \\
\hline
\end{tabular}

\begin{tabular}{|c|c|c|c|c|c|c|c|c|c|c|c|c|}
\hline HH \& Indivdual Controls & yes & yes & yes & yes & yes & yes & yes & yes & yes & yes & yes & yes \\
\hline Food Source Controls & yes & yes & yes & yes & yes & yes & yes & yes & yes & yes & yes & yes \\
\hline Zip Code Fixed Effects & yes & yes & yes & yes & yes & yes & yes & yes & yes & yes & yes & yes \\
\hline ler Identification (p-value) & - & 0.476 & - & - & 0.110 & - & - & 0.001 & - & - & 0.000 & - \\
\hline rer Identification (p-value) & - & 0.932 & - & - & 0.869 & - & - & 0.253 & - & - & 0.804 & - \\
\hline Endogeneity (p-value) & - & 0.016 & - & - & 0.019 & - & - & 0.010 & - & - & 0.104 & - \\
\hline ergen-Paap (robust F-Stat) & - & 0.663 & - & - & 2.01 & - & - & 6.79 & - & - & 21.95 & - \\
\hline Anderson-Rubin (p-value) & - & 0.049 & - & - & 0.064 & - & - & 0.019 & - & - & 0.049 & - \\
\hline Observations & 960 & 792 & 792 & 955 & 788 & 788 & 947 & 781 & 781 & 959 & 792 & 792 \\
\hline
\end{tabular}

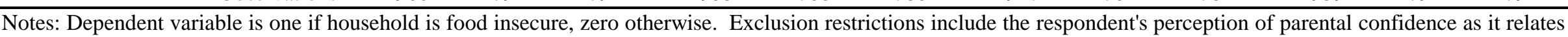

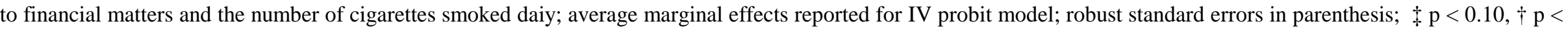
0.05 , and $* \mathrm{p}<0.01$. 